University of Wollongong

Research Online

Faculty of Engineering and Information

Faculty of Engineering and Information

Sciences - Papers: Part A

Sciences

$1-1-2016$

\title{
Microstructure and micro-texture evolution during the dynamic recrystallisation of a $\mathrm{Ni}-30 \mathrm{Fe}-\mathrm{Nb}-\mathrm{C}$ model alloy
}

Parvez Mannan

University of Wollongong, pm999@uowmail.edu.au

Ahmed A. Saleh

University of Wollongong, asaleh@uow.edu.au

Azdiar A. Gazder

University of Wollongong, azdiar@uow.edu.au

Gilberto Casillas

University of Wollongong, gilberto@uow.edu.au

Elena V. Pereloma

University of Wollongong, elenap@uow.edu.au

Follow this and additional works at: https://ro.uow.edu.au/eispapers

Part of the Engineering Commons, and the Science and Technology Studies Commons

Research Online is the open access institutional repository for the University of Wollongong. For further information contact the UOW Library: research-pubs@uow.edu.au 


\title{
Microstructure and micro-texture evolution during the dynamic recrystallisation of a Ni-30Fe-Nb-C model alloy
}

\author{
Abstract \\ The evolution of microstructure and micro-texture during discontinuous dynamic recrystallisation of an \\ austenitic $\mathrm{Ni}-30 \mathrm{Fe}-\mathrm{Nb}-\mathrm{C}$ model alloy subjected to interrupted plane strain compression at strains $(\varepsilon)$ of \\ $0.23,0.35,0.68,0.85$ and 1.2 was investigated using electron backscattering diffraction and transmission \\ electron microscopy. Throughout the strain range, the majority of dynamic recrystallisation events \\ comprised nucleation in necklace-like arrangements located at and along grain boundaries via bulging. At \\ $\varepsilon \geq 0.68$, discrete nucleation events were also observed within grain interiors. Grain growth during \\ dynamic recrystallisation is characteristic of strain induced boundary migration. The initial texture \\ comprised Cube-RD $(\{013\}\langle 100\rangle)$, Cube-ND $(\{001\}\langle 310\rangle)$ and Cube $(\{001\}\langle 100\rangle)$ orientations. Up \\ to $\varepsilon \leq 0.35$, the unrecrystallised grain fractions comprised the Brass $(\{110\}\langle 112\rangle)$ or Copper \\ $(\{112\}\langle 111\rangle)$ orientations and an intensity spread near Rotated Goss $(\{011\}\langle 011\rangle)$. Between $0.68 \leq \varepsilon$ \\ $\leq 1.2$, the texture of the unrecrystallised grain fractions was similar to that of the recrystallised grains \\ throughout the strain range; both of which are dominated by the Cube orientation. The dominance of the \\ Cube orientation in the secondary deformed and recrystallised grains can be ascribed to its low stored \\ energy and orientation stability.

\section{Keywords} \\ $\mathrm{nb}, 30 \mathrm{fe}$, ni, recrystallisation, dynamic, alloy, during, model, evolution, texture, micro, microstructure, c

\section{Disciplines} \\ Engineering | Science and Technology Studies

\section{Publication Details} \\ Mannan, P., Saleh, A. A., Gazder, A. A., Casillas, G. \& Pereloma, E. V. (2016). Microstructure and micro- \\ texture evolution during the dynamic recrystallisation of a Ni-30Fe-Nb-C model alloy. Journal of Alloys and \\ Compounds, 689 250-265.
}




\title{
Microstructure and micro-texture evolution during the dynamic recrystallisation of a Ni-30Fe-Nb-C model alloy
}

\author{
Parvez Mannan ${ }^{\mathrm{a}}$, Ahmed A. Saleh ${ }^{\mathrm{a}}$, Azdiar A. Gazder ${ }^{\mathrm{b}}$, Gilberto Casillas ${ }^{\mathrm{b}}$, Elena V. Pereloma ${ }^{\mathrm{a}, \mathrm{b}}$ \\ ${ }^{a}$ School of Mechanical, Materials and Mechatronics Engineering, University of Wollongong, \\ Wollongong, New South Wales 2522, Australia \\ ${ }^{b}$ Electron Microscopy Centre, University of Wollongong, Wollongong, New South Wales 2500,
} Australia

\begin{abstract}
The evolution of microstructure and micro-texture during discontinuous dynamic recrystallisation of an austenitic $\mathrm{Ni}-30 \mathrm{Fe}-\mathrm{Nb}-\mathrm{C}$ model alloy subjected to interrupted plane strain compression at strains $(\varepsilon)$ of $0.23,0.35,0.68,0.85$ and 1.2 was investigated using electron backscattering diffraction and transmission electron microscopy. Throughout the strain range, the majority of dynamic recrystallisation events comprised nucleation in necklace-like arrangements located at and along grain boundaries via bulging. At $\varepsilon \geq 0.68$, discrete nucleation events were also observed within grain interiors. Grain growth during dynamic recrystallisation is characteristic of strain induced boundary migration. The initial texture comprised Cube-RD $(\{013\}\langle 100\rangle)$, Cube-ND $(\{001\}\langle 310\rangle)$ and Cube $(\{001\}\langle 100\rangle)$ orientations. Up to $\varepsilon \leq 0.35$, the unrecrystallised grain fractions comprised the Brass $(\{110\}\langle 112\rangle)$ or Copper $(\{112\}\langle 111\rangle)$ orientations and an intensity spread near Rotated Goss $(\{011\}\langle 011\rangle)$. Between $0.68 \leq \varepsilon \leq 1.2$, the texture of the unrecrystallised grain fractions was similar to that of the recrystallised grains throughout the strain range; both of which are dominated by the Cube orientation. The dominance of the Cube orientation in the secondary deformed and recrystallised grains can be ascribed to its low stored energy and orientation stability.
\end{abstract}

\section{Keywords}

Ni-Fe; dynamic recrystallization; nucleation; texture; electron back-scattering diffraction (EBSD); transmission electron microscopy (TEM)

* Corresponding author:

Ahmed A. Saleh

Tel.: +61242213034

Fax: +61242213662

email: asaleh@uow.edu.au 


\section{Introduction}

Characterising high temperature austenitic microstructures is important to gain insights into the hot deformation behaviour of conventional steels processed above their face-centred-cubic (fcc) $\leftrightarrow$ body-centred-cubic (bcc) allotropic transformation temperatures. However, in most cases the direct observation of the fcc austenite formed at high temperatures is very difficult; as bcc products (such as ferrite, pearlite, bainite and/or martensite) resulting from fcc decomposition/transformation develop upon subsequent cooling and eliminate/conceal the prior austenite microstructure. In addition, the room temperature micro-texture of remnant austenite (if any) may not contain all the orientations that existed in the bulk texture of the fully austenitic microstructure at high temperatures; as the latter tends to be affected by preferential phase transformation during cooling.

To overcome these difficulties, model alloys comprising stable, single phase, fcc austenite (such as 304 and 316L stainless steels and Ni-30Fe) are typically used to characterise deformation behaviour at high temperatures [1-3]. In this regard, 304 SS and 316L stainless steels are the less preferred alternative on account of their low stacking fault energy $\left(\mathrm{SFE}=21-23 \mathrm{~mJ} / \mathrm{m}^{2}[4,5]\right)$ which results in stacking faults and/or deformation twinning upon deformation at $\sim 700-800{ }^{\circ} \mathrm{C}$ [6]. On the other hand, the SFE of Ni-30Fe $\left(50-60 \mathrm{~mJ} / \mathrm{m}^{2}\right.$ [7]) is closer to that of C-Mn steel [8]. Consequently, this model alloy does not form stacking faults or deformation twins over the 700-900 ${ }^{\circ} \mathrm{C}$ temperature range [3] and develops a crystallographic texture that is similar to the hot deformation of conventional low carbon, high-strength-low-alloy or micro-alloyed steels.

During hot deformation, two processes are concurrent namely, work hardening and work softening. The first is associated with the generation of new dislocations and results in an increase in the accumulated strain. The second is linked to a rearrangement of the dislocation substructure and results in a reduction in dislocation density and stored energy. Work softening takes place during either: (i) the discontinuous dynamic recrystallisation (DRX) of low to medium SFE materials; where new dislocation-free grains nucleate from deformed grains and subsequently grow or, (ii) the continuous dynamic recrystallisation (also known as dynamic recovery) of high SFE materials; where new grains appear by subgrain formation and growth [9, 10]. Here the SFE level influences the motion of dislocations and thus the softening phenomena such that dislocation climb and cross-slip are widely prevalent in high SFE materials but are extremely limited in low SFE materials [11].

During DRX the high strain incompatibilities across original grain boundaries and the local accumulation of high dislocation densities near them leads to corrugated or serrated boundaries [12]. New grains nucleate when the protuberance of serrated boundaries is accompanied by a rotation of a bulged portion [1, 13-17] or by twinning at the back of a bulged segment [15]. Although the nucleation mechanism during DRX is quite clear, microstructure evolution during 
DRX is disputed. Roberts et al. [18] suggests that DRX is initially manifested by a necklace of new grains at original grain boundaries. After these nucleation sites are fully occupied, DRX progresses sequentially via continuous nucleation at and along the more recently created interfaces between recrystallised grains and the deformed matrix. On the other hand, while Ponge and Gottstein [19] agree with the creation of an initial necklace of grains, they argue that subsequent DRX occurs via irregular nucleation and growth events.

Texture evolution in the deformed matrix of $\mathrm{Ni}-30 \mathrm{Fe}-\mathrm{Nb}-\mathrm{C}$ subjected to hot plane strain compression between $700-900{ }^{\circ} \mathrm{C}$ at $1 \mathrm{~s}^{-1}$ strain rate is characterised by orientations along the $\alpha$ fibre (extending from the Goss $(\mathrm{G},\{110\}\langle 001\rangle)$ to the Brass (B, $\{110\}\langle 112\rangle)$ orientations [20-22]) and $\beta$-fibre (extending from the $\mathrm{Cu}(\{112\}\langle 111\rangle)$ to the $\mathrm{B}$ through the $\mathrm{S}(\{123\}\langle 634\rangle)$ orientations $[23,24])$ along with weak Cube $(C,\{100\}\langle 001\rangle)$ orientations [25]. These orientations and fibres are retained in the DRX texture with increasing strain (up to $\varepsilon=1$ at $900{ }^{\circ} \mathrm{C}, 1 \mathrm{~s}^{-1}$ strain rate [25]) or at higher strain rates $\left(\varepsilon=0.6\right.$ at $950{ }^{\circ} \mathrm{C}, 10 \mathrm{~s}^{-1}$ strain rate [26]). While the overall DRX texture intensity is significantly weaker than the deformed matrix, the $\mathrm{C}$ orientations are relatively stronger than the other orientations.

Wusatowska-Sarnek et al. [15] and Hasegawa et al. [27] also observed a weakening of the DRX texture during the hot compression of copper and argued that the texture was increasingly "randomised" with the progress of DRX. Hasegawa et al. [27] ascribed this phenomenon to the high frequency of annealing twins. Contrarily, Guria et al. [28] reported a strong cube DRX texture in 316 stainless steel subjected to plane strain compression at $950-1100{ }^{\circ} \mathrm{C}$ and attributed this to multiple annealing twins and grain rotation during deformation.

Recently, the authors reported the effect of thermo-mechanical processing (TMP) parameters (temperature and strain rate) on the DRX behaviour of $\mathrm{Ni}-\mathrm{Fe}-\mathrm{Nb}-\mathrm{C}$ model alloys subjected to plane strain compression up to $\varepsilon=1.2$ [29]. In the current work, electron backscattering diffraction (EBSD) and transmission electron microscopy (TEM) are used to track the evolution of microstructure and micro-texture during DRX of a $\mathrm{Ni}-\mathrm{Fe}-\mathrm{Nb}-\mathrm{C}$ model alloy subjected to plane strain compression at $1075^{\circ} \mathrm{C}$.

\section{Experimental and analytical procedure}

A model alloy with nominal composition $69.7 \mathrm{Ni}-29.8 \mathrm{Fe}-0.33 \mathrm{Nb}-0.04 \mathrm{C}$ wt. $\%$ was cast at McMaster University, Canada [7] as a $45 \mathrm{~kg}$ ingot, reheated to $1250{ }^{\circ} \mathrm{C}$ for 24 hours to break down the as-cast structure and then hot rolled in 6 passes from $60 \mathrm{~mm}$ to $30 \mathrm{~mm}$. Thereafter an intermediate solution treatment was undertaken at $1350{ }^{\circ} \mathrm{C}$ for 30 minutes followed by hot rolling in 4 passes to $15 \mathrm{~mm}$ thick plate and immediately water quenched. Both first and second hot rolling 
stages were completed at temperatures $>1050{ }^{\circ} \mathrm{C}$. The $15 \mathrm{~mm}$ plates were then subjected to a final solution treatment at $1225^{\circ} \mathrm{C}$ for $\sim 20$ hours.

$20 \times 15 \times 10 \mathrm{~mm}^{3}$ samples were cut from the $15 \mathrm{~mm}$ thick plate along the rolling (RD), normal (ND) and transverse (TD) directions, respectively. Plane strain compression tests were performed on a Gleeble 3500 TMP simulator in hydra-wedge mode in concurrence with the prior rolling convention. Consequently, during plane strain compression, the compression direction was parallel to the ND such that the samples extended along the RD and were constrained along the TD. It follows that the rolling convention is used throughout the text.

A schematic of the TMP schedule is shown in Fig. 1a. In order to track the evolution of microstructure and micro-texture during DRX, six samples were used. Each sample was re-heated to $1250{ }^{\circ} \mathrm{C}$ at $5{ }^{\circ} \mathrm{Cs}^{-1}$ and held for $300 \mathrm{~s}$ to dissolve any $\mathrm{NbC}$ precipitates followed by an $\varepsilon_{\text {rough }}=0.3$ roughing reduction at $0.1 \mathrm{~s}^{-1}$ strain rate at the same temperature in order to reduce the initial grain size. The first sample was cooled to $1075{ }^{\circ} \mathrm{C}$ at $3{ }^{\circ} \mathrm{Cs}^{-1}$ and immediately water quenched. Throughout the text, this particular sample is denoted by a true strain $(\varepsilon)=0$ and is referred to as the initial sample. Following this, the remaining samples were subsequently deformed to $\varepsilon=0.23,0.35$, $0.68,0.85$ and 1.2 at $0.1 \mathrm{~s}^{-1}$ strain rate followed by water quenching at each strain level.

For EBSD measurements, the samples were sectioned in two halves along the RD-ND plane (Fig. 1b), mechanically polished up to 2000 grit and then electropolished at room temperature on a Struers Lectropol-5 using an electrolyte of $73 \%$ methanol $+10 \%$ butoxyethanol $+9 \%$ distilled water $+8 \%$ perchloric acid operating at $17 \mathrm{~V}, \sim 0.52-0.56 \mathrm{~mA}$ for $180 \mathrm{~s}$.

Due to the variation in through thickness strain associated with friction and material flow during TMP, extreme care was taken to obtain EBSD maps from the middle area of each sample. EBSD was conducted on a JEOL-JSM7001F field emission gun-scanning electron microscope equipped with a Nordlys-II(S) camera and the Oxford Instruments AZtec acquisition software suite operating at $15 \mathrm{kV}, \sim 5 \mathrm{nA}$ and $15 \mathrm{~mm}$ working distance. Depending on the deformation strain, step sizes of $1 \mu \mathrm{m}(\varepsilon=0.23,0.35,0.68$ and 0.85$)$ and $0.5 \mu \mathrm{m}(\varepsilon=1.2)$ were used. Due to the coarse grain size at $\varepsilon=0$, an additional map was acquired with a step size of $10 \mu \mathrm{m}$ in order to obtain statistically representative texture information.

The initial post-processing of all EBSD maps was undertaken using Oxford Instruments Channel-5 software. Map artefacts were removed by constantly maintaining a minimum spatial resolution of three times the step size. In all EBSD maps, subgrain/grain structures are defined by misorientations $(\theta) \geq 2^{\circ}$. Consequently, low angle grain boundaries (LAGBs) are defined as having $2^{\circ} \leq \theta<15^{\circ}$ misorientations whereas the total high angle grain boundaries (THAGBs) comprise high angle boundaries (HAGBs) $\left(15^{\circ} \leq \theta \leq 57.5^{\circ}\right)$ and twin boundaries (TBs). First order annealing TBs are defined as $\Sigma 3=60^{\circ}\langle 111\rangle$ while second order twins are defined by $\Sigma 9=38.9^{\circ}$ 
$\langle 110\rangle$. The maximum tolerance of the misorientation angle $(\Delta \theta)$ from the exact axis-angle relationship was identified by the Palumbo-Aust criterion (i.e. $\Delta \theta \leq 15^{\circ} \Sigma^{-5 / 6}$ ) [30] yielding a tolerance limit of $6^{\circ}$ for $\Sigma 3$ and $2.4^{\circ}$ for $\Sigma 9$, respectively. The orientation distribution functions (ODFs) $\left(\phi_{2}=0^{\circ}, 45^{\circ}\right.$ and $65^{\circ}$ sections) are depicted using Bunge's notation after exporting EBSD data to JTex [31].

Similar to previous studies [32-35], a grain orientation spread (GOS) criterion was applied to segment the partially recrystallised EBSD maps into dynamically recrystallised and unrecrystallised fractions. The GOS criterion is a long range measure of variations in internal misorientation and is defined as the average misorientation of all pixel pairs within a (sub)grain [32]. Here (sub)grains with a GOS $\leq 2^{\circ}$ are classified as dynamically recrystallised whereas (sub)grains with GOS $>2^{\circ}$ are considered to be unrecrystallised. While the recrystallised fraction strictly comprises a set of grains that are recrystallised at any given strain, the unrecrystallised fraction is a complex mixture of originally deformed, recovered and secondary deformed grains. It follows that the sub-fractions of unrecrystallised grains changes with increasing strain. Segmenting these unrecrystallised sub-fractions requires tracking the same set of grains throughout the strain range. Thus, such segmentation was not possible in the present study; as different samples were used for each strain level.

The intragranular local misorientation was computed for the whole map as well as individual recrystallised and unrecrystallised fractions. This is defined as the mean misorientation between a central pixel and its surrounding pixels in a $3 \times 3$ matrix of immediate neighbours [36]. Misorientations greater than $2^{\circ}$ were not considered in order to exclude (sub)grain boundaries. The relative frequency of the intragranular local misorientation distribution was fitted to a log-normal probability distribution function:

$$
f\left(\theta_{\text {local }}\right)=\frac{1}{w \theta_{\text {local }} \sqrt{2 \pi}} \exp \frac{-\left(\ln \theta_{\text {local }} / \theta_{c}\right)^{2}}{2 w^{2}}
$$

where, $w$ and $\theta_{c}$ are the width and median of the L-N distribution of $\theta_{\text {local }}$. The associated mean $\left(\theta_{m}\right)$ and standard deviation $\left(\mu_{\theta}\right)$ were determined as follows:

$$
\begin{gathered}
\theta_{m}=\theta_{c} \exp \left(\frac{w^{2}}{2}\right) \\
\mu_{\theta}=\theta_{c} \exp \left(\frac{w^{2}}{2}\right) \sqrt{\exp \left(w^{2}-1\right)}
\end{gathered}
$$


For TEM analysis, $0.3 \mathrm{~mm}$ thick slices were cut from the middle of the TD-ND plane (Fig. 1b) using a Struers Accutom-50. The slices were manually polished up to 2000 grit ( $70 \mu \mathrm{m}$ thickness) following which $\emptyset 3 \mathrm{~mm}$ discs were punched out. The discs were twin-jet electropolished at $-30{ }^{\circ} \mathrm{C}$ on a Struers Tenupol -5 using an electrolyte of $90 \%$ methanol and $10 \%$ perchloric acid operating at $30 \mathrm{~V}, \sim 150 \mathrm{~mA}$. TEM was carried out on a probe-corrected cold field emission gun JEOL JEM-ARM200F operating at $200 \mathrm{kV}$. Inner and outer collection angles were 50 and $180 \mathrm{mrad}$, respectively for high-angle annular dark field imaging while a collection angle of $11 \mathrm{mrad}$ was used to acquire bright-field images. Both sets of images were obtained for a dwell time of $38 \mu$ s and a probe current of $35 \mathrm{pA}$.

\section{Results and discussion}

Fig. 2a shows the true stress versus true strain curve up to $\varepsilon=1.2$ with the solid red circles depicting $\varepsilon=0,0.23,0.35,0.68,0.85$ and 1.2 at which EBSD and TEM were undertaken. The flow curve exhibits a broad stress peak and continuous softening up to $\varepsilon=1.2$ without reaching the steady state condition that is typically associated with DRX [12, 14, 37, 38]. Similarly broad stress peaks have been previously observed in $\mathrm{Ni}-30 \mathrm{Fe}$ and $\mathrm{Ni}-30 \mathrm{Fe}-\mathrm{Nb}-\mathrm{C}$ subjected to hot plane strain compression [25]. The absence of the steady state condition can be ascribed to the relatively coarse initial grain size $(181 \pm 110 \mu \mathrm{m}$ without considering twins as boundaries). This is in contrast to our previous DRX work [29] on the same alloy with a smaller initial grain size $(114 \pm 40 \mu \mathrm{m})$; where the steady state condition was reached under similar hot deformation conditions. The above is in agreement with Fernández et al. [39] who reported that smaller initial grain sizes promote DRX and assist in reaching the steady state condition earlier during hot deformation.

Fig. 2a can also be used to estimate the evolution of DRX fraction as a function of true strain. TableCurve-2D software was used to initially fit the flow curve, following which the critical $\left(\varepsilon_{\mathrm{c}}\right)$, peak $\left(\varepsilon_{\mathrm{p}}\right)$ and maximum softening $\left(\varepsilon_{\mathrm{m}}\right)$ strains were obtained from the fitted first and second derivatives [29]. These values were used to calculate the DRX fraction via the following Avramitype equation [40]:

$$
X_{D R X}=1-\exp \left[-0.693\left(\frac{\varepsilon-\varepsilon_{c}}{\varepsilon_{m}-\varepsilon_{c}}\right)^{2}\right]
$$

The DRX fractions from Eq. (4) and EBSD -based segmentation are shown in Fig. 2b. The disparity between the two results is discussed in more detail in Section 3.1 given below.

\subsection{Microstructure evolution with dynamic recrystallisation}

Fig. 3 comprises inverse pole figure maps that track the evolution of the DRX microstructure with progressively increasing strain whereas Fig. 4 depicts the same maps after 
segmentation into recrystallised (Figs. 4 a, c, e, g, i) and unrecrystallised (Figs. 4 b, d, f, h, j) fractions.

The $\varepsilon=0$ initial microstructure is characterised by nearly equiaxed grains (when twin boundaries are not considered as grain boundaries) with uniform orientation contrast, a high fraction of $\Sigma 3$ (Fig. 3a) and a small fraction of $\Sigma 9$ (not shown in Fig. 3a) annealing twin boundaries. The initial grain size with and without considering twin boundaries as grain boundaries is $\sim 90 \pm 75$ and $\sim 181 \pm 110 \mu \mathrm{m}$, respectively. The high fractions of annealing twin boundaries return peaks at $60^{\circ}$ $(\Sigma 3)$ and $38.9^{\circ}(\Sigma 9)$ of the misorientation distribution histogram (Figs. 5a) and constitute $\sim 41 \%$ and $6.3 \%$ of the grain boundary area fraction, respectively (Fig. 5b). The low fraction of $\Sigma 9$ could be ascribed to the limited impingement of $\Sigma 3$ boundaries as the former is formed by the twin reaction: $\Sigma 3+\Sigma 3=\Sigma 9[41]$.

At $\varepsilon=0.23$ (Figs. $3 \mathrm{~b}$, 4a and $4 \mathrm{~b}$ ), the grains have begun to elongate and return slightly higher orientation contrast. A few recrystallised grains are readily observable along the original grain boundaries (Figs. 4a and 4b). At $\varepsilon=0.35$ (Figs. 3c, 4c and 4d), the deformation is apparent and a clear necklace of recrystallised grains decorate the original grain boundaries (Figs. 4c and 4d). At $\varepsilon=0.68,0.85$ and 1.2 , the microstructure comprises a significant fraction of recrystallised grains as seen in Figs. 3d-3f and Figs. 4 e, g, i.

With the onset of deformation at $\varepsilon=0.23$, a reduction in the HAGB, THAGB, $\Sigma 3$ and $\Sigma 9$ fractions is seen; following which they all exhibit a gradual increase at higher strains (Fig. 5b).

The overall refining effect of DRX on the microstructure is apparent in Fig. 5c; where the initial grain size of $\sim 90 \pm 75 \mu \mathrm{m}$ (considering twins as boundaries) at $\varepsilon=0$ drastically reduces to an average recrystallised grain size of $\sim 13 \pm 10 \mu \mathrm{m}$ between $\varepsilon=0.23$ and 1.2.

The large disparity between the recrystallised fractions estimated from Eq. (4) and EBSDbased segmentation (Figs. 2b and Figs. 4a, 4c, 4e, 4g, 4i) can be linked to the differences in their underlying assumptions. Eq. (4) overestimates the dynamically recrystallised fraction as it cumulatively calculates the DRX fraction and does not account for secondary deformation with increasing strain. On the other hand, the GOS threshold criterion returns an apparent underestimate as it strictly accounts for the recrystallised grains at any given strain (Figs. 4a, 4c, 4e, 4g, 4i). Consequently, grains that nucleated at lower strains and/or underwent secondary deformation at higher strains are not part of the recrystallised fraction (Figs. 4b, 4d, 4f, 4h, 4j). It follows that the estimates obtained from the two methods cannot be expected to match each other and as such, should not be compared at all.

The intragranular local misorientation is analogous to the geometrically necessary dislocation (GND) density such that local areas of large intragranular misorientations correspond to higher densities of GNDs and allude to strain heterogeneity [33, 36]. The intragranular local 
misorientation maps are presented in Figs. 6a-6e with the frequency distribution $\left(\theta_{\text {local }}\right)$ and mean intragranular local misorientation $\left(\theta_{\mathrm{m}}\right)$ shown in Figs. $7 \mathrm{a}$ and $7 \mathrm{~b}$, respectively for all strain levels.

At $\varepsilon=0.23$, higher intragranular local misorientations are mostly concentrated along the grain boundaries (Fig. 6a). Such local misorientation gradients at grain boundaries create differential pressure across them; resulting in corrugation or serration and bulge formation. The bulging phenomenon is in line with the nucleation and growth of DRX grains by the strain-induced boundary migration (SIBM) mechanism proposed by Beck and Sperry [42] based on optical microscopy and later confirmed by Bailey and Hirsch via TEM [43]. While the unrecrystallised grains are being progressively consumed by the recrystallised grains (Figs. 6b-6d), the former also acquire higher intragranular local misorientations up to $\varepsilon=0.85$ (Fig. 7). This is manifested as a shift in the relative frequency distribution and its mean $\left(\theta_{\mathrm{m}}\right)$ towards higher intragranular local misorientation values along with larger standard deviations.

At $\varepsilon=1.2$, the microstructure comprises a large fraction of recrystallised grains (Fig. 4i) with the unrecrystallised fraction mostly comprising secondary deformed grains and a few remnant original grains (Fig. 4j). Correspondingly, Fig. 6e records lower intragranular local misorientations compared to $\varepsilon=0.85$ (Fig. 6d). This is also reflected as a shift in the relative frequency distribution and its mean $\left(\theta_{\mathrm{m}}\right)$ to lower intragranular local misorientation values (Fig. 7).

Since step sizes of $1 \mu \mathrm{m}$ (for $\varepsilon=0,0.23,0.35,0.68$ and 0.85 ) and $0.5 \mu \mathrm{m}$ (for $\varepsilon=1.2$ ) were used for EBSD mapping and we imposed a minimum spatial resolution of three times the step size, the smallest quantifiable microstructural feature is either 3 or $1.5 \mu \mathrm{m}$, respectively. Since the above step/feature sizes may be too large to elucidate some microstructural aspects, TEM was employed to help delineate smaller substructures and early nucleation events.

Representative bright-field images of substructure development with increasing strain are shown in Fig. 8. The few scattered dislocations observed within grain interiors (Fig. 8a) at $\varepsilon=0$ are replaced by dislocation accumulation at boundaries and tangled arrays of dislocations within grain interiors (Figs. 8b-8e), the formation of dislocation cell structures (Figs. 8d-8e) followed by cell block subdivision into dense dislocation walls, the formation of subgrains and the progressive rotation of their boundaries from low-angle to high-angle character (Figs. 8d-8f). Interestingly, the substructures at $\varepsilon=1.2$ (Fig. 8f) are somewhat similar to that at $\varepsilon=0.23$ (Fig. 8b) with dislocation pile-ups at grain boundaries and dislocation walls/subgrains associated with substructure development of secondary deformed recrystallised grains. Again, all of the above aspects are characteristic of SIBM [43].

The details inferred from intragranular local misorientation maps can be compared with TEM observations. In Fig. 9, magnified views of selected regions of interest from the intragranular local misorientation maps (Fig. 6, demarcated by rectangular red boxes) are shown. From Fig. 9a, it 
is clear that the intragranular local misorientation maps are very similar to TEM images (Figs. 8b and 9d) such that they both portray a concentration of defects at grain boundaries due to the accommodation of strain inhomogeneity during plastic deformation as well as high defect concentrations in areas behind bulged boundaries and near triple junctions. The limited substructure development within grains at $\varepsilon=0.23$ evolves into a network of geometrically necessary dislocations at $\varepsilon=0.35$ comprising clearly defined cells with low misorientation contrast within their interiors. This correlates very well with TEM observations of dislocation network development and subgrain formation with dislocation-free interiors (Figs. 8c and 9e). At $\varepsilon=0.68$ and together with the further development of subgrain structures, the interior of deformed grains evidences strain accumulation with higher local misorientation contrast (Fig. 9c) and the presence of small strain-free DRX grains, whereas some coarser DRX grains which formed earlier exhibit higher local misorientations due to secondary deformation. The bright-field images in Figs. 8d and 9f also show an increase in dislocation density with a relatively uniform distribution of dislocations within the interiors of deformed grains coupled with subgrain formation. Although statistically stored dislocations are not accounted for by EBSD, the intragranular local misorientation maps are able to reasonably depict the evolution of defect substructures with strain. Additionally, while individual dislocations are not visible in the intragranular local misorientation maps, the arrangements of dislocations in low angle configurations such as dislocation cells and/or subgrain boundaries or high angle configurations with pile-ups at grain boundaries are clearly visible.

Representative bright-field images of early nucleation events are shown in Figs. 10 and 11. As mentioned above, nucleation is preceded by the bulging of original grain boundaries. Bulging is typically accompanied by the formation of dislocation networks, dislocation cells or sub-boundaries and/or annealing twin boundaries.

In the present polycrystalline $\mathrm{Ni}-30 \mathrm{Fe}-\mathrm{Nb}-\mathrm{C}$, nucleation was found either at original boundaries or within original grain interiors. As seen in Figs. 10a-10c, nucleation at original boundaries occurred via sub-boundary completion such that annealing twins did not always form behind the bulge. This is different from the findings of Miura et al. [44] on copper bi-crystals subjected to tensile loading at $650{ }^{\circ} \mathrm{C}$ at strain rate $4.2 \times 10^{-4} \mathrm{~s}^{-1}$. They reported nucleation via bulging and the predominant formation of annealing twin $(\Sigma 3)$ boundaries behind the bulges. The bulging of original grain boundaries is said to be accompanied by the formation of twin boundaries at low strain rate and/or high temperature or sub-boundaries at high strain rate and/or lower temperatures $[12,45]$. In this study, bulged boundaries expand via sub-boundary as well as twin formation as plane strain compression was undertaken at a moderate temperature and strain rate $\left(1075^{\circ} \mathrm{C}, 0.1 \mathrm{~s}^{-1}\right)$. 
At low strains, nucleation also occurred within unrecrystallised grain interiors at original twin boundaries. An example of this is given at $\varepsilon=0.23$ in Figs. 10d-10f. The selected area diffraction pattern (Fig. 10e) along the $[01 \overline{1}]_{T} \|[01 \overline{1}]_{M}$ zone axes (where the subscripts $\mathrm{T}$ and $\mathrm{M}$ represent the twin and matrix, respectively) confirms the twin with further validation provided by the dark field image using the $[\overline{2} 00]_{T}$ spot (Fig. 10f).

At high strains, isolated nucleation events were also observed within grain interiors (Fig. 11). Examples of this are given at $\varepsilon=0.68$ (Fig. 11a) and 0.85 (Fig. 11b) and bright-field images (Figs. 11f and 11g).

The leftmost, second and third arrows in Fig. 11a provide examples of dynamically recrystallised nuclei forming by subgrain rotation; whereby low-angle subgrain boundaries absorb dislocations originating at subgrain interiors and gradually evolve into high-angle boundaries. These three nuclei display an intermediate stage of development compared to the rightmost nuclei; such that the former are partially surrounded by high-angle boundaries whereas the latter is completely enclosed by high-angle boundaries. The boundary of the nucleus demarcated by the rightmost white arrow in Fig. 11a exhibits a misorientation angle/axis with the unrecrystallised matrix of $\sim 38^{\circ}-41^{\circ}$ $\langle 221\rangle$ (Fig. 11c) whereas the boundaries of the left and right nuclei in Fig. 11b exhibit $\sim 39^{\circ}-45^{\circ}$ $\langle 332\rangle$ (Fig. 11d) and $\sim 30^{\circ}-34^{\circ}\langle 221\rangle$ (Fig. 11e), respectively. The above spread of misorientation angles/axes is close to the commonly reported $30^{\circ}-40^{\circ}\langle 111\rangle$ relationship that favours the growth of cube - oriented grains during static recrystallisation [46].

From the current observations, the nucleation and growth of recrystallised grains evolve by both, the successive development of necklace -type layers and irregular, isolated nucleation events occurring within the grain interior. The latter was previously observed during the hot compression of 304 stainless steel [1].

\subsection{Micro-texture evolution with dynamic recrystallisation}

The ideal orientations of texture components in fcc materials are represented schematically for the $\phi_{2}=0^{\circ}, 45^{\circ}$ and $65^{\circ}$ ODF sections in Fig. 12 and listed in Table 1.

Due to the coarse grain size at $\varepsilon=0$, the ODF shown in Fig. 13 was calculated from an EBSD map acquired with a step size of $10 \mu \mathrm{m}$ in order to obtain statistically representative texture information. Alternatively, the ODFs shown in Figs. 14-16 were calculated from the EBSD IPF maps shown in Figs. 3 (full maps) and 4 (recrystallised and unrecrystallised fractions) which were acquired with step sizes of $1 \mu \mathrm{m}$ (for $\varepsilon=0,0.23,0.35,0.68$ and 0.85 ) and $0.5 \mu \mathrm{m}$ (for $\varepsilon=1.2$ ).

The initial texture at $\varepsilon=0$ mainly comprises C-RD $(\{013\}\langle 100\rangle)$ and weak spread between the C-ND $(\{001\}\langle 310\rangle)$ and $\mathrm{C}$ orientations (Fig. 13a). In addition to the former orientations, the texture of the full map at $\varepsilon=0.23$ and 0.35 also comprises $\mathrm{B}$ and $\mathrm{Cu}$ orientations and an intensity 
spread near Rt-G as seen in Figs. 14a and 14b, respectively. At $\varepsilon \geq 0.68$, the $\mathrm{C}$ orientation becomes dominant and intensifies with increasing strain. This is accompanied by weaker intensities along the $\alpha$-fibre and the $\mathrm{Cu}$ and $\sim \mathrm{S}$ orientations (Figs. 14c-14e).

The unrecrystallised texture at $\varepsilon=0.23$ returns intensity spreads along $\Phi$ near the $\mathrm{B}$ and $\mathrm{Cu}$ orientations and an intensity split around Rt-G (Fig. 15a). At $\varepsilon=0.35$, increasing deformation lead to stronger intensities along the $\alpha$-fibre accompanied by orientation splitting at $\sim \phi_{1}=45^{\circ}, \Phi=45^{\circ}$, $\phi_{2}=0^{\circ}$ (Fig. 15b). At $\varepsilon \geqslant 0.68$, the orientations of the unrecrystallised textures (Figs. 15c-15e) mirror those of the full map (Figs. 14c-14e) with a dominant and intensifying $\mathrm{C}$ orientation along with weaker intensities for the $\alpha$-fibre and the $\mathrm{Cu}$ and $\sim \mathrm{S}$ orientations.

From the onset of strain, the recrystallised texture shows a continuous strengthening of the $\mathrm{C}$ orientation such that it dominates the final DRX texture at $\varepsilon=1.2$ (Fig. 16). A weak intensity spread is also seen along the $\alpha$-fibre and near the $\sim \mathrm{S}$ and CT orientations (Figs. 16c-16e).

While the above results contradict reports of a weak C oriented DRX texture during the hot plane strain compression of Ni-30Fe alloy [47-49], they are in agreement with Guria et al [28] who also observed a pronounced C oriented DRX texture after the plane strain compression of 316 stainless steel.

In order to investigate the weak spread near CT orientation for $\varepsilon \geq 0.68$, the recrystallised grains were sub-divided into two subsets on the basis of their orientation into $\mathrm{C}$ and non- $\mathrm{C}$ oriented grains with a deviation of $15^{\circ}$ from their ideal positions. Fig. $5 \mathrm{~d}$ shows a clear preference for $\Sigma 3$ boundary formation in non-C oriented grains; which in turn explains that despite the dominance of $\mathrm{C}$ orientations, the intensity of the CT orientation remains low (Figs. 16c-16e).

From the observations in Figs. 15 and 16, by $\varepsilon=0.68$ the original deformation texture (Figs. $15 \mathrm{a}$ and $15 \mathrm{~b})$ was replaced by $\mathrm{C}$ orientations that originated via recrystallisation and thereafter underwent subsequent secondary deformation (Figs. 16a-16c). As a consequence, beyond $\varepsilon \geqslant 0.68$ the unrecrystallised and recrystallised ODFs are similar and denote the nucleation, growth and secondary deformation of mostly $\mathrm{C}$ orientations.

In the case of plane strain compression, the $\mathrm{C}$ orientation possesses the lowest Taylor factor (or low stored energies) when calculated using octahedral slip systems for fcc materials [24]. This underlying causative could be behind the present proliferation of $\mathrm{C}$ oriented grains; such that one of the explanations related to $\mathrm{C}$ texture evolution during the static recrystallisation of medium to high SFE fcc materials might also be applicable to DRX. Ridha and Hutchinson [50] pointed out that C oriented grains deformed by plane strain compression were more susceptible to recovery since their active slip systems had orthogonal and thus elastically non-interacting, Burgers vectors [51]; as a result of which they exhibit low stored energy. Consequently, the dominance of recrystallised C 
orientations can be ascribed to the overall stability of the secondary deformed C oriented grains and their low stored energies.

\section{Conclusions}

Microstructure and micro-texture evolution during the dynamic recrystallisation of a Ni$30 \mathrm{Fe}-\mathrm{Nb}-\mathrm{C}$ model alloy when subjected to plane strain compression at $1075{ }^{\circ} \mathrm{C}$ up to $\varepsilon=1.2$ was investigated via EBSD and TEM. The results showed that: (i) the majority of nucleation occurred in necklace-like arrangements located at and along grain boundaries via bulging. At $\varepsilon \geq 0.68$, nucleation was also observed within grain interiors. The growth of these nucleated grains occurred via strain induced boundary migration. (ii) Between $0.68 \leq \varepsilon \leq 1.2$, the texture of the unrecrystallised grain fractions was similar to that of the recrystallised grains throughout the strain range; both of which are dominated by the Cube orientation. The dominance of the Cube orientation can be ascribed to its low stored energy and its orientation stability during secondary deformation.

\section{Acknowledgements}

The authors are grateful to the Australian Research Council and BlueScope Steel Ltd. for financially supporting this work via the ARC LP110100231 grant. The JEOL 7001F and JEOL ARM200F were funded by Australian Research Council grants LE0882813 and LE120100104, respectively.

\section{References}

[1] A. Belyakov, H. Miura, T. Sakai, Dynamic recrystallization under warm deformation of a 304 type austenitic stainless steel, Materials Science and Engineering A, 255 (1998) 139-147.

[2] M.F. Abbod, C.M. Sellars, A. Tanaka, D.A. Linkens, M. Mahfouf, Effect of changing strain rate on flow stress during hot deformation of type 316L stainless steel, Materials Science and Engineering A, 491 (2008) 290-296.

[3] A.S. Taylor, P. Cizek, P.D. Hodgson, Comparison of 304 stainless steel and Ni-30 wt.\% Fe as potential model alloys to study the behaviour of austenite during thermomechanical processing, Acta Materialia, 59 (2011) 5832-5844.

[4] P.J. Ferreira, P. Müllner, A thermodynamic model for the stacking-fault energy, Acta Materialia, 46 (1998) 4479-4484.

[5] M.A. Meyers, Y.B. Xu, Q. Xue, M.T. Pérez-Prado, T.R. McNelley, Microstructural evolution in adiabatic shear localization in stainless steel, Acta Materialia, 51 (2003) 1307-1325.

[6] P.J. Hurley, P.D. Hodgson, B.C. Muddle, A study of deformation substructures in austenite using a model Ni-30 wt.\% Fe alloy, Scripta Materialia, 45 (2001) 25-32.

[7] H.S. Zurob, Effects of precipitation, recovery and recrystallization on the microstructural evolution of microalloyed austenite, in: Engineering, McMaster University, Hamilton, Ontario, Canada, 2003, pp. 102-104.

[8] E.J. Palmeire, P. Cizek, F. Bai, R.M. Poths, J. Turner, B.P. Wynne, W.M. Rainforth, The use of $\mathrm{Fe}-30 \% \mathrm{Ni}$ and $\mathrm{Fe}-30 \% \mathrm{Ni}-\mathrm{Nb}$ alloys as model systems for studying the microstructural evolution during the hot deformation of austenite, Materials and Manufacturing Processes, 26 (2011) 127131. 
[9] C.M. Sellars, W.J. McTegart, On the mechanism of hot deformation, Acta Metallurgica, 14 (1966) 1136-1138.

[10] F.J. Humphreys, H. Haterly, Recrystallisation and releated annealing phenomena, Second edition ed., Elsevier Oxford, 2004.

[11] I.L. Dillamore, The stacking fault energy dependence of the mechanisms of deformation in Fcc metals, Metallurgical Transactions, 1 (1970) 2463-2470.

[12] T. Sakai, A. Belyakov, R. Kaibyshev, H. Miura, J.J. Jonas, Dynamic and post-dynamic recrystallization under hot, cold and severe plastic deformation conditions, Progress in Materials Science, 60 (2014) 130-207.

[13] S. Saki, T. Sakai, K. Takeishi, Hot deformation of austenite in a plain C steel, Trans. ISIJ 17 (1977) 718-725.

[14] T. Sakai, J.J. Jonas, Overview no. 35 Dynamic recrystallization: Mechanical and microstructural considerations, Acta Metallurgica, 32 (1984) 189-209.

[15] A.M. Wusatowska-Sarnek, H. Miura, T. Sakai, Nucleation and microtexture development under dynamic recrystallization of copper, Materials Science and Engineering: A, 323 (2002) 177186.

[16] T. Sakai, M. Ohashi, Dislocation substructures developed during dynamic recrystallisation in polycrystalline nickel, Materials Science and Technology, 6 (1990) 1251-1257.

[17] A. Belyakov, H. Miura, T. Sakai, Dynamic recrystallization under warm deformation of polycrystalline copper, ISIJ International, 38 (1998) 595-601.

[18] W. Roberts, H. Boden, B. Ahlblom, Dynamic recrystallization kinetics, Metal Science, 13 (1979) 195-205.

[19] D. Ponge, G. Gottstein, Necklace formation during dynamic recrystallization: mechanisms and impact on flow behavior, Acta Materialia, 46 (1998) 69-80.

[20] A.A. Saleh, C. Haase, E.V. Pereloma, D.A. Molodov, A.A. Gazder, On the evolution and modelling of brass-type texture in cold-rolled twinning-induced plasticity steel, Acta Materialia, 70 (2014) 259-271.

[21] J. Hirsch, K. Lücke, M. Hatherly, Overview No. 76: Mechanism of deformation and development of rolling textures in polycrystalline f.c.c. Metals-III. The influence of slip inhomogeneities and twinning, Acta Metallurgica, 36 (1988) 2905-2927.

[22] A.A. Saleh, E.V. Pereloma, A.A. Gazder, Texture evolution of cold rolled and annealed Fe24Mn-3Al-2Si-1Ni-0.06C TWIP steel, Materials Science and Engineering: A, 528 (2011) 45374549.

[23] T. Leffers, R.K. Ray, The brass-type texture and its deviation from the copper-type texture, Progress in Materials Science, 54 (2009) 351-396.

[24] J.J. Sidor, R.H. Petrov, L.A.I. Kestens, Modeling the crystallographic texture changes in aluminum alloys during recrystallization, Acta Materialia, 59 (2011) 5735-5748.

[25] A.S. Taylor, P. Cizek, P.D. Hodgson, Orientation dependence of the substructure characteristics in a Ni-30Fe austenitic model alloy deformed in hot plane strain compression, Acta Materialia, 60 (2012) 1548-1569.

[26] M.F. Abbod, C.M. Sellars, D.A. Linkens, M. Mahfouf, P. Cizek, Modeling the flow behavior, recrystallization, and crystallographic texture in hot-deformed Fe-30 Wt Pct Ni Austenite, Metallurgical and Materials Transactions A: Physical Metallurgy and Materials Science, 38 (2007) 2400-2409.

[27] M. Hasegawa, M. Yamamoto, H. Fukutomi, Formation mechanism of texture during dynamic recrystallization in $\gamma$-TiAl, nickel and copper examined by microstructure observation and grain boundary analysis based on local orientation measurements, Acta Materialia, 51 (2003) 3939-3950. [28] A. Guria, G.K. Mandal, P. Hodgson, J.H. Beynon, S.G. Chowdhury, Effect of twinning on microstructural evolution during dynamic recrystallisation of hot deformed as-cast austenitic stainless steel, Metallurgical and Materials Transactions A: Physical Metallurgy and Materials Science, 46 (2015) 4423-4428. 
[29] P. Mannan, A.G. Kostryzhev, H. Zurob, E.V. Pereloma, Hot deformation behaviour of Ni30Fe-C and $\mathrm{Ni}-30 \mathrm{Fe}-\mathrm{Nb}-\mathrm{C}$ model alloys, Materials Science and Engineering: A, 641 (2015) 160171.

[30] G. Palumbo, K.T. Aust, Structure-dependence of intergranular corrosion in high purity nickel, Acta Metallurgica et Materialia, 38 (1990) 2343-2352.

[31] J.-J. Fundenberger, B. Beausir, Université de Lorraine - Metz, 2015, JTEX - Software for texture analysis, http://jtex-software.eu/.

[32] M.H. Alvi, S. Cheong, H. Weiland, A.D. Rollett, Recrystallization and texture development in hot rolled 1050 aluminum, in: Materials Science Forum, 2004, pp. 357-362.

[33] A.A. Gazder, M. Sánchez-Araiza, J.J. Jonas, E.V. Pereloma, Evolution of recrystallization texture in a 0.78 wt.\% Cr extra-low-carbon steel after warm and cold rolling, Acta Materialia, 59 (2011) 4847-4865.

[34] A.A. Gazder, A.A. Saleh, E.V. Pereloma, Microtexture analysis of cold-rolled and annealed twinning-induced plasticity steel, Scripta Materialia, 65 (2011) 560-563.

[35] A.A. Gazder, V.Q. Vu, A.A. Saleh, P.E. Markovsky, O.M. Ivasishin, C.H.J. Davies, E.V. Pereloma, Recrystallisation in a cold drawn low cost beta titanium alloy during rapid resistance heating, Journal of Alloys and Compounds, 585 (2014) 245-259.

[36] A.A. Saleh, E.V. Pereloma, A.A. Gazder, Microstructure and texture evolution in a twinninginduced-plasticity steel during uniaxial tension, Acta Materialia, 61 (2013) 2671-2691.

[37] E.I. Poliak, J.J. Jonas, Critical strain for dynamic recrystallization in variable strain rate hot deformation, ISIJ International, 43 (2003) 692-700.

[38] E.I. Poliak, J.J. Jonas, Initiation of dynamic recrystallization in constant strain rate hot deformation, ISIJ International, 43 (2003) 684-691.

[39] A.I. Fernández, P. Uranga, B. López, J.M. Rodriguez-Ibabe, Dynamic recrystallization behavior covering a wide austenite grain size range in $\mathrm{Nb}$ and $\mathrm{Nb}-\mathrm{Ti}$ microalloyed steels, Materials Science and Engineering: A, 361 (2003) 367-376.

[40] M. Shaban, B. Eghbali, Determination of critical conditions for dynamic recrystallization of a microalloyed steel, Materials Science and Engineering: A, 527 (2010) 4320-4325.

[41] V. Randle, Mechanism of twinning-induced grain boundary engineering in low stacking-fault energy materials, Acta Materialia, 47 (1999) 4187-4196.

[42] P.A. Beck, P.R. Sperry, Strain Induced Grain Boundary Migration in High Purity Aluminum, Journal of Applied Physics, 21 (1950) 150-152.

[43] J.E. Bailey, P.B. Hirsch, The recrystallization process in some polycrystalline metals, Proceedings of the Royal Society of London A: Mathematical, Physical and Engineering Sciences, 267 (1962) 11-30.

[44] H. Miura, T. Sakai, R. Mogawa, J.J. Jonas, Nucleation of dynamic recrystallization and variant selection in copper bicrystals, Philosophical Magazine, 87 (2007) 4197-4209.

[45] H. Miura, H. Aoyama, T. Sakai, Effect of grain-boundary misorientation on dynamic recrystallization of $\mathrm{Cu}-\mathrm{Si}$ bicrystals, Nippon Kinzoku Gakkaishi/Journal of the Japan Institute of Metals, 58 (1994) 267-275.

[46] B. Hutchinson, The cube texture revisited, in: Materials Science Forum, 2012, pp. 3-10.

[47] P. Cizek, F. Bai, E.J. Palmiere, W.M. Rainforth, EBSD study of the orientation dependence of substructure characteristics in a model $\mathrm{Fe}-30 \mathrm{wt} \% \mathrm{Ni}$ alloy subjected to hot deformation, Journal of Microscopy, 217 (2005) 138-151.

[48] H. Beladi, P. Cizek, P.D. Hodgson, On the characteristics of substructure development through dynamic recrystallization, Acta Materialia, 58 (2010) 3531-3541.

[49] P.D. Hodgson, P. Cizek, A.S. Taylor, H. Beladi, Texture evolution and softening processing in an austenitic $\mathrm{Ni}-30 \mathrm{Fe}$ alloy subjected to hot deformation and subsequent annealing, Material Science Forum, 702-703 (2012) 435-438.

[50] A.A. Ridha, W.B. Hutchinson, Recrystallisation mechanisms and the origin of cube texture in copper, Acta Metallurgica, 30 (1982) 1929-1939. 
[51] I. Samajdar, R.D. Doherty, Role of S[(123)<634>] orientations in the preferred nucleation of cube grains in recrystallization of fcc metals, Scripta Metallurgica et Materialia, 32 (1995) 845-850. 


\section{Tables}

Table 1. Euler angles, Miller indices and fibres of the common texture components in fcc metals and alloys.

\begin{tabular}{|c|c|c|c|c|c|c|}
\hline \multirow{2}{*}{ Texture component } & \multirow{2}{*}{ Symbol } & \multicolumn{3}{|c|}{ Euler angles } & \multirow{2}{*}{ Miller indices } & \multirow{2}{*}{ Fibre } \\
\hline & & $\phi_{1}$ & $\Phi$ & $\phi 2$ & & \\
\hline Cube (C) & 東 & 45 & 0 & 45 & $\{100\}\langle 001\rangle$ & - \\
\hline Cube-RD (C-RD) & $\notin$ & 0 & 22 & $0 / 90$ & $\{013\}\langle 100\rangle$ & - \\
\hline Cube-ND (C-ND) & $\otimes$ & 22 & 0 & $0 / 90$ & $\{001\}\langle 310\rangle$ & - \\
\hline Cube Twin (CT) & & $27 / 63$ & 48 & $27 / 63$ & $\{122\}\langle 212\rangle$ & - \\
\hline Goss (G) & & 90 & 90 & 45 & $\{110\}\langle 001\rangle$ & $\alpha / \tau$ \\
\hline G/B & $\mathrm{O}$ & 74 & 90 & 45 & $\{110\}\langle 115\rangle$ & $\alpha$ \\
\hline Brass (B) & $\mathbb{\theta}$ & 55 & 90 & 45 & $\{110\}\langle 112\rangle$ & $\alpha / \beta$ \\
\hline Rotated Goss (Rt-G) & & 0 & 90 & 45 & $\{011\}\langle 011\rangle$ & $\alpha$ \\
\hline Rotated Cube (Rt-C) & $\gg$ & $0 / 90$ & 0 & 45 & $\{001\}\langle 110\rangle$ & $\tau$ \\
\hline Copper $(\mathrm{Cu})$ & & 90 & 35 & 45 & $\{112\}\langle 111\rangle$ & $\tau / \beta$ \\
\hline$S$ & (4) & 59 & 37 & 63 & $\{123\}\langle 634\rangle$ & $\beta$ \\
\hline
\end{tabular}




\section{$\underline{\text { Figures }}$}

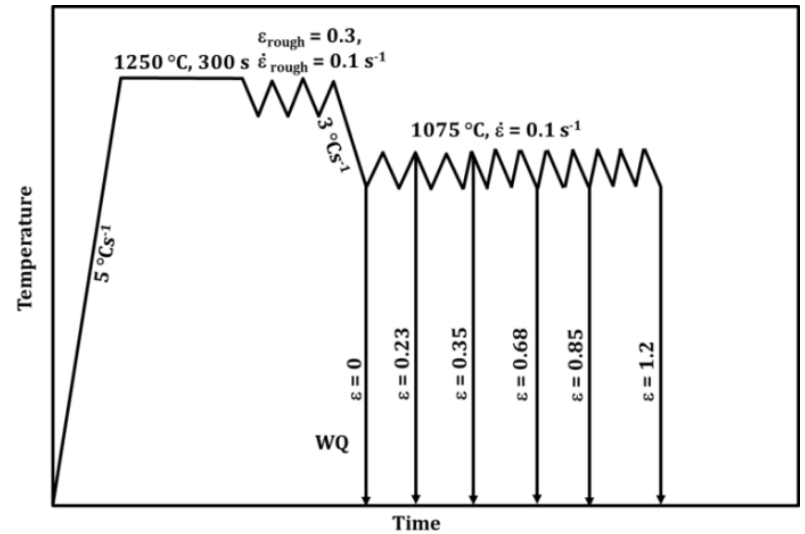

(a)

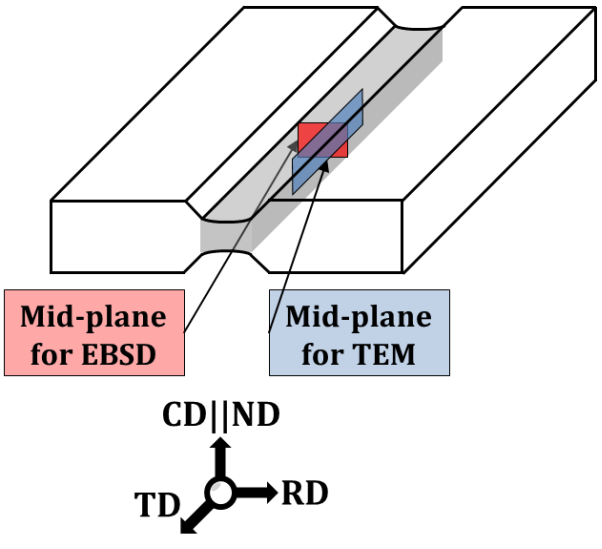

(b)

Figure 1. Schematic representation of (a) the employed thermo-mechanical processing schedule and (b) the as-processed Gleeble sample.

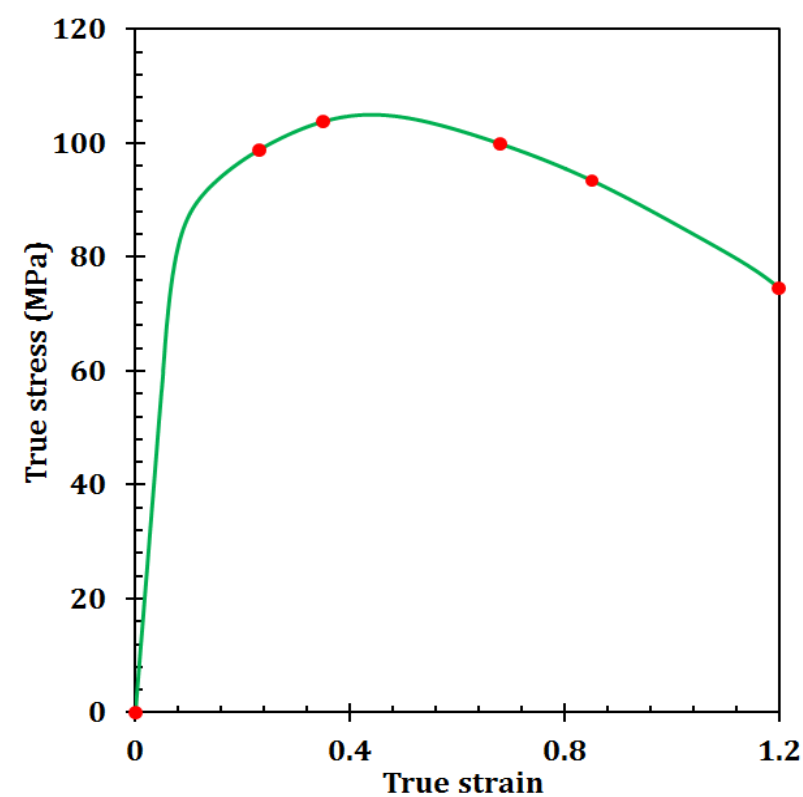

(a)

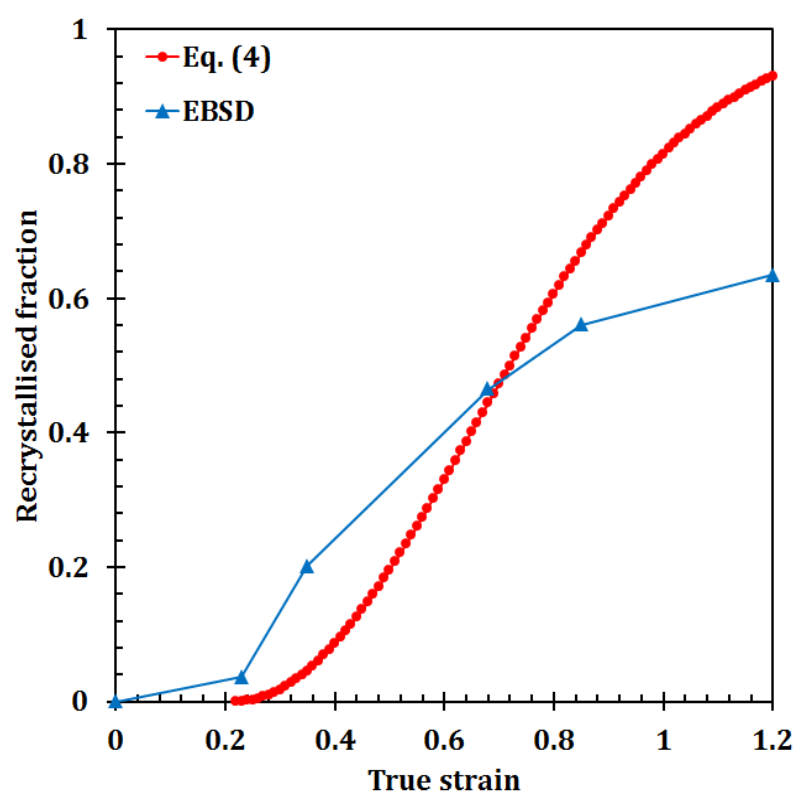

(b)

Figure 2. (a) True stress versus true strain curve up to $\varepsilon=1.2$ with the solid red circles depicting $\varepsilon=$ 0, 0.23, 0.35, 0.68, 0.85 and 1.2 at which EBSD and TEM were undertaken. (b) Dynamically recrystallised fractions estimated via Eq.(4) and EBSD-based segmentation. 


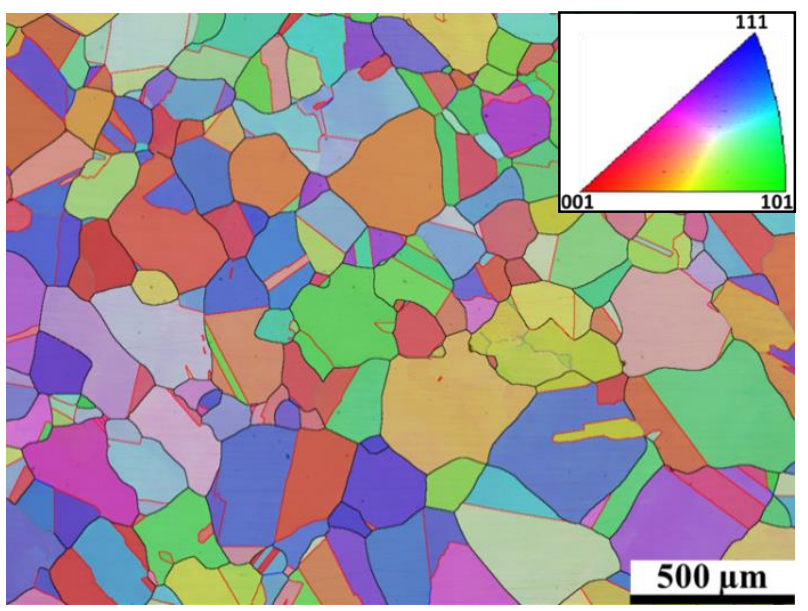

(a)

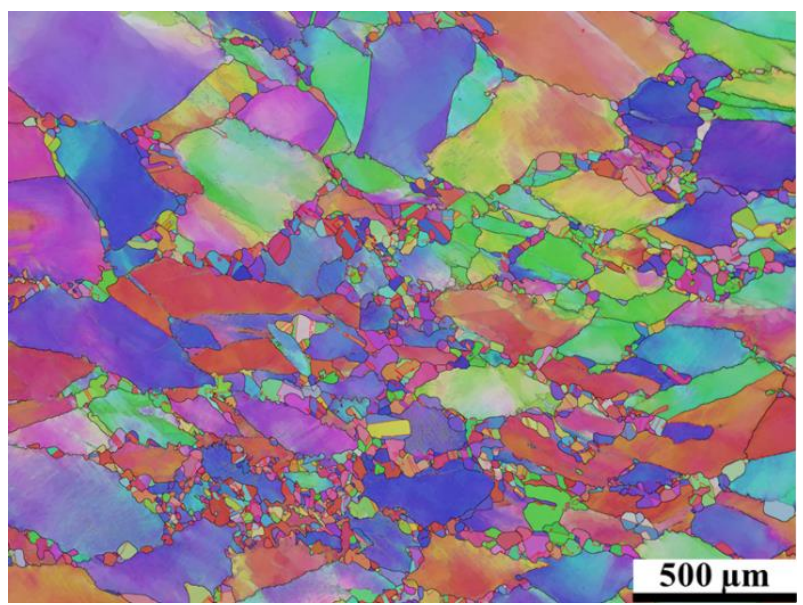

(c)

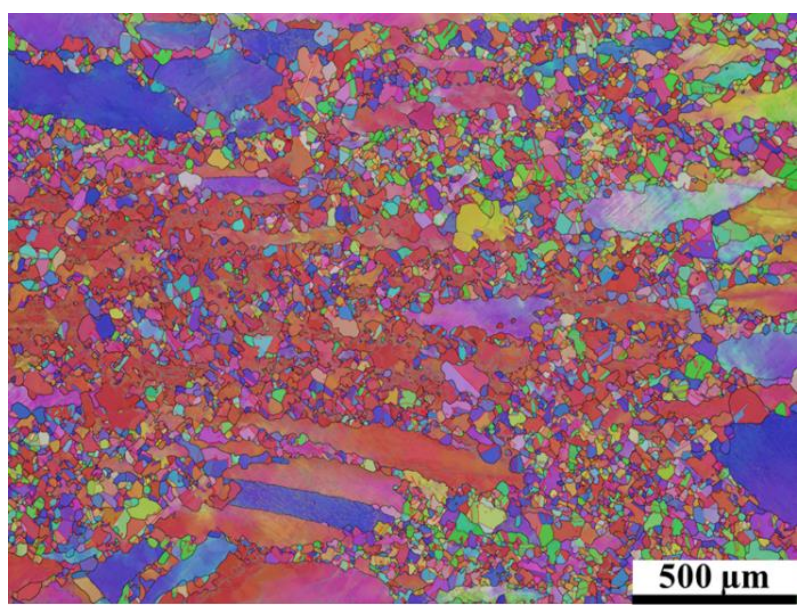

(e)

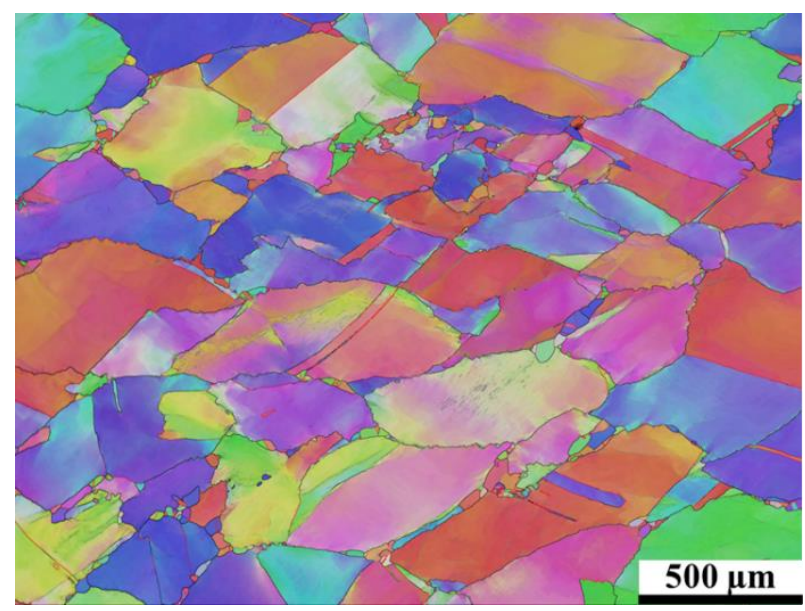

(b)

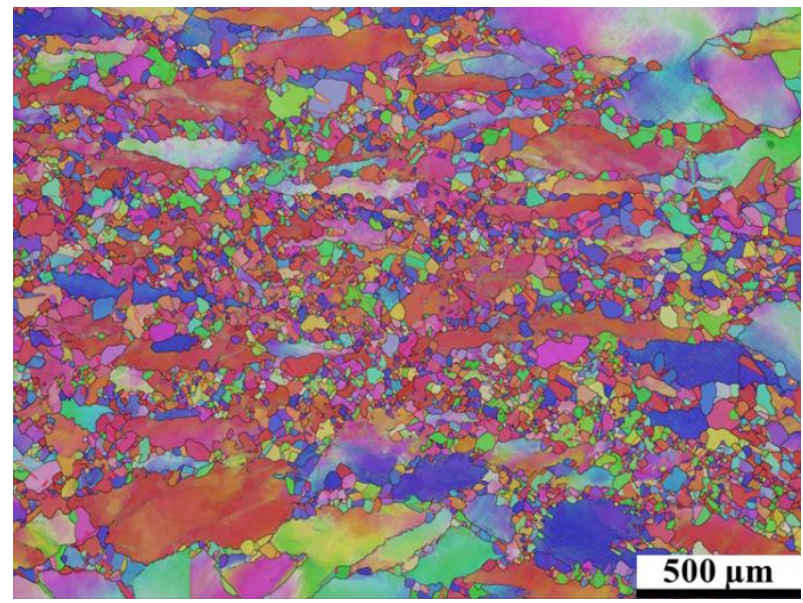

(d)

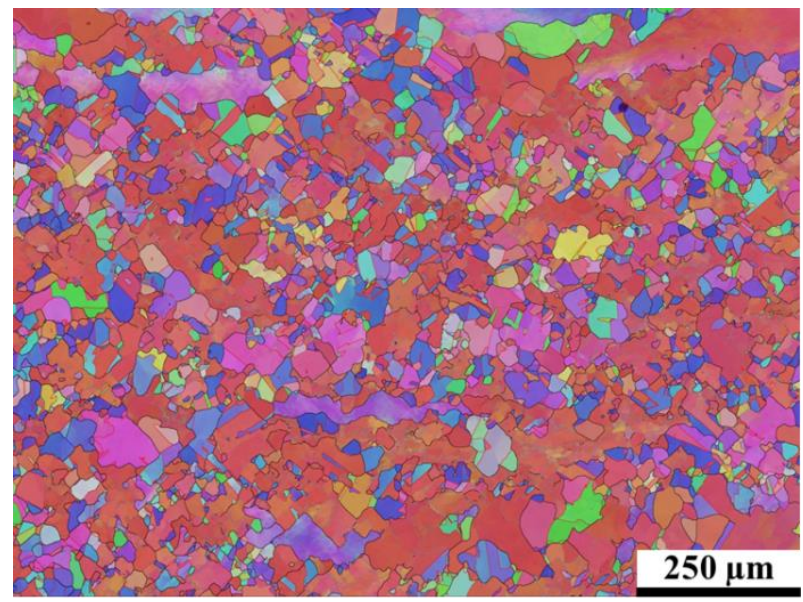

(f)

Figure 3. Inverse pole figure (IPF) maps at true strains of (a) 0, (b) 0.23, (c) 0.35 , (d) 0.68, (e) 0.85, and (f) 1.2. LAGBs = grey, HAGBs = black, $\Sigma 3\left(60^{\circ}\langle 111\rangle\right)=$ red. $\mathrm{RD}=$ horizontal; $\mathrm{ND}=$ vertical. 


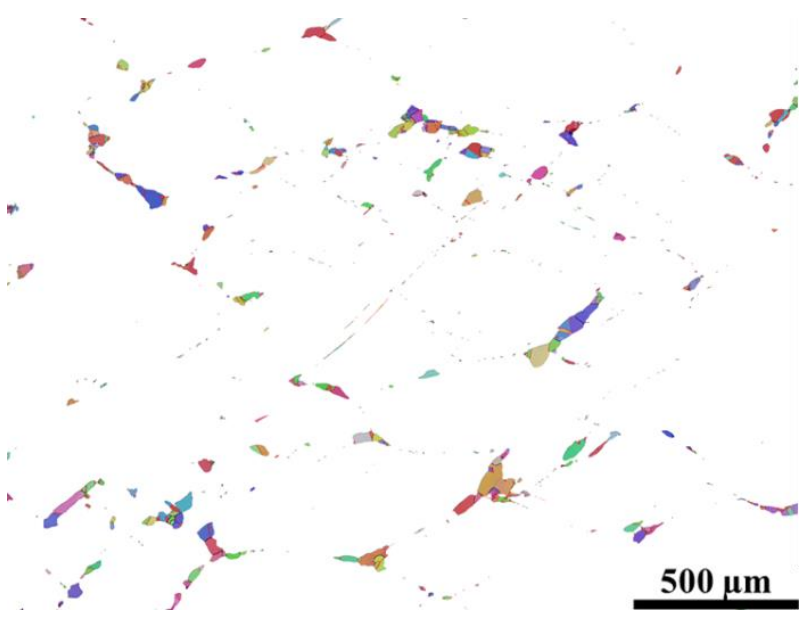

(a)

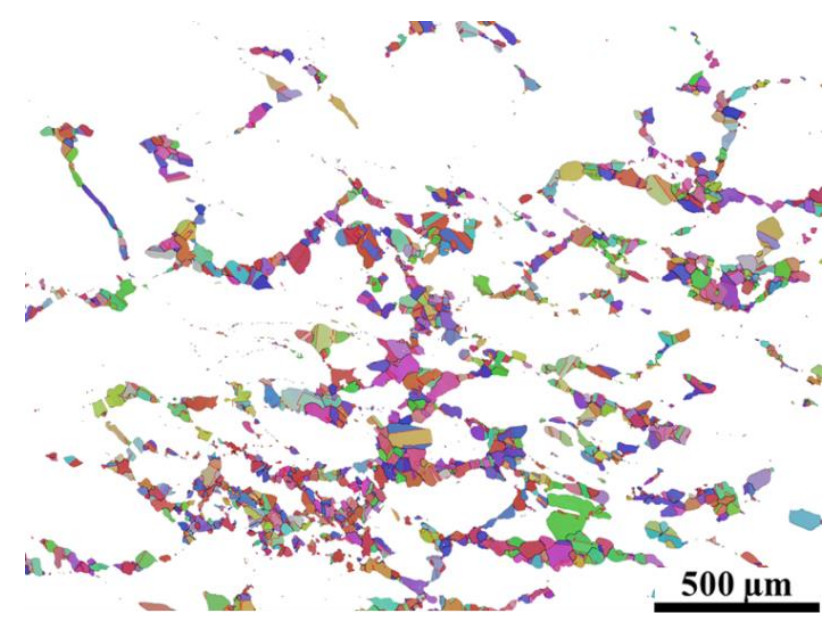

(c)

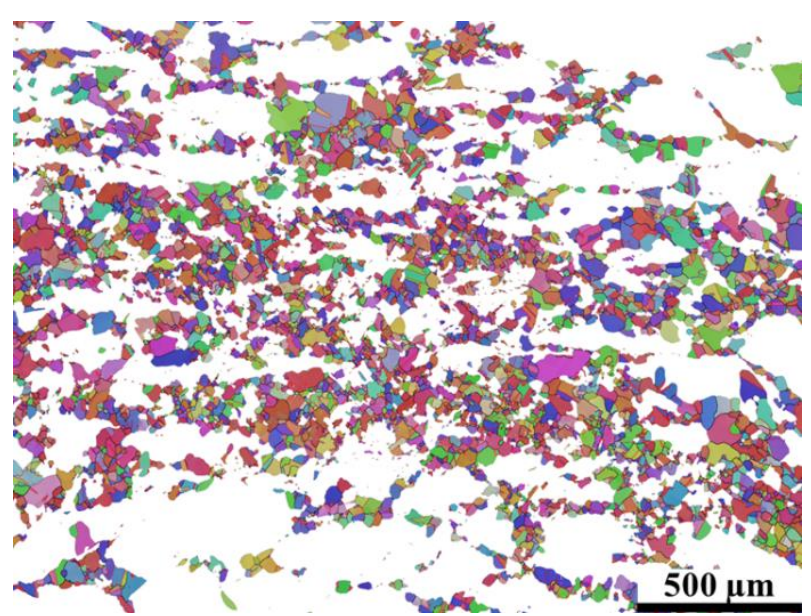

(e)

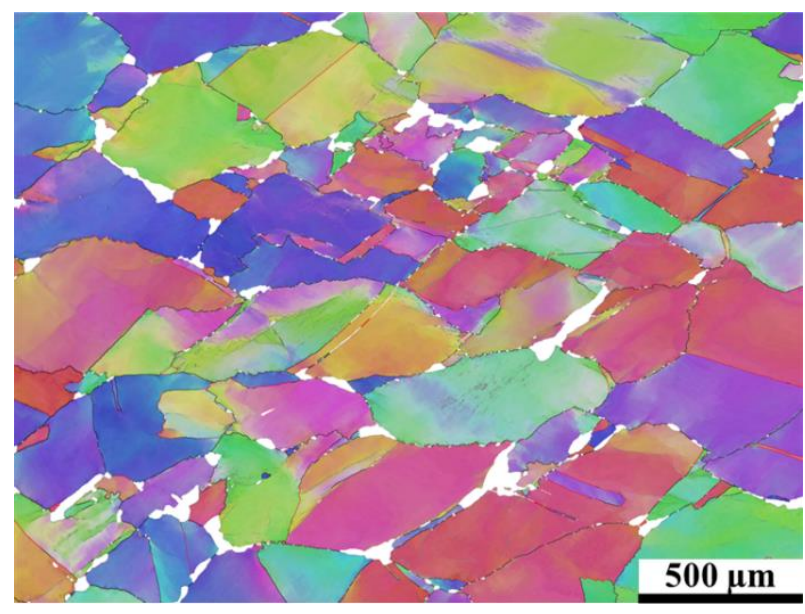

(b)

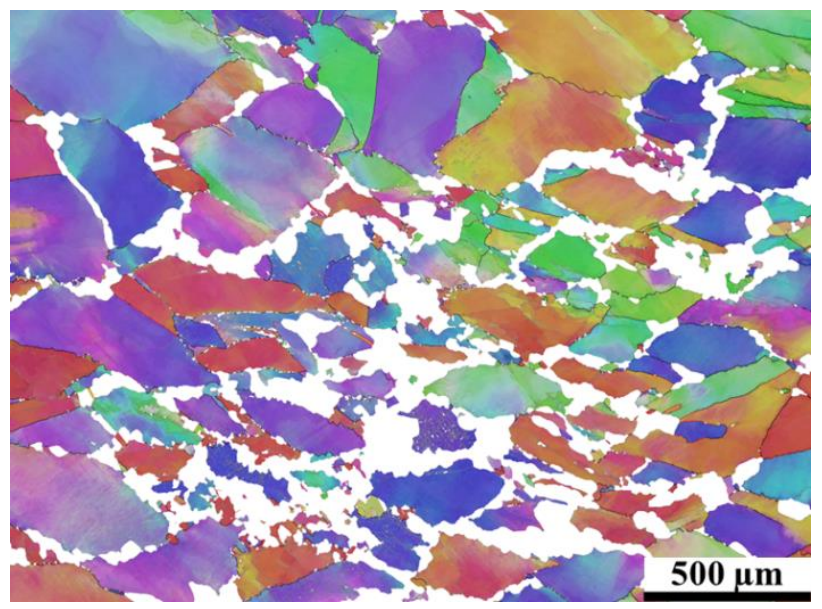

(d)

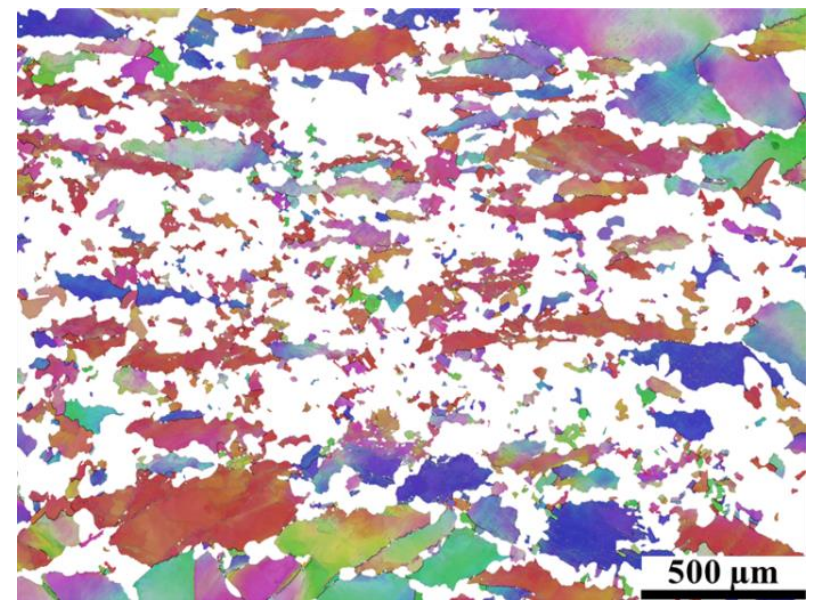

(f) 


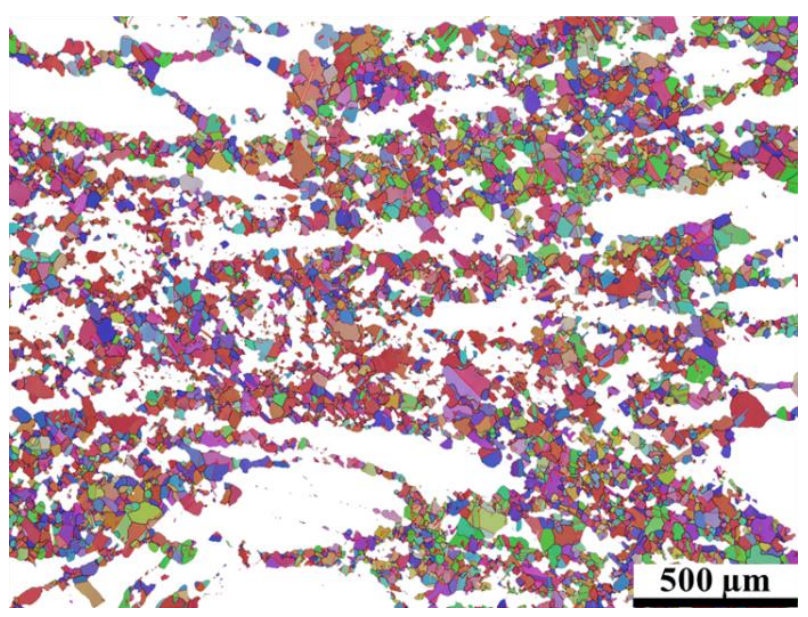

$(\mathrm{g})$

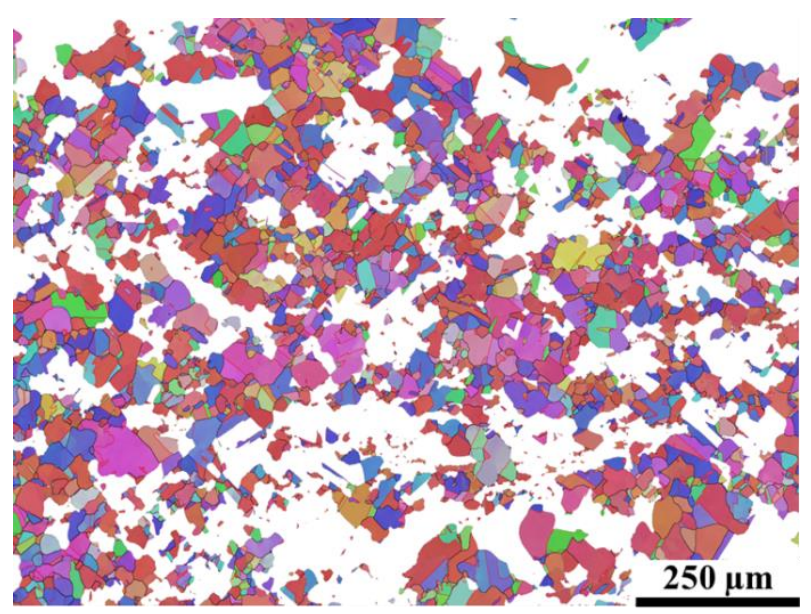

(i)

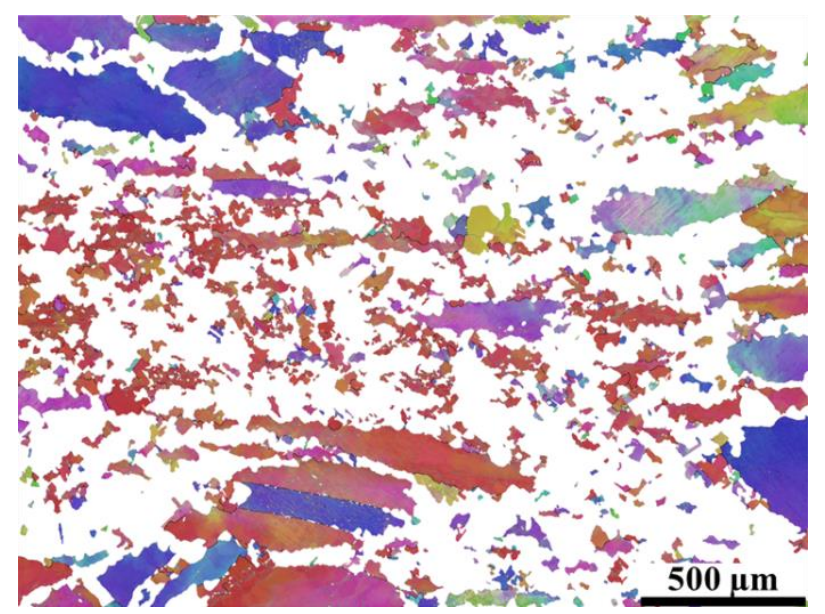

(h)

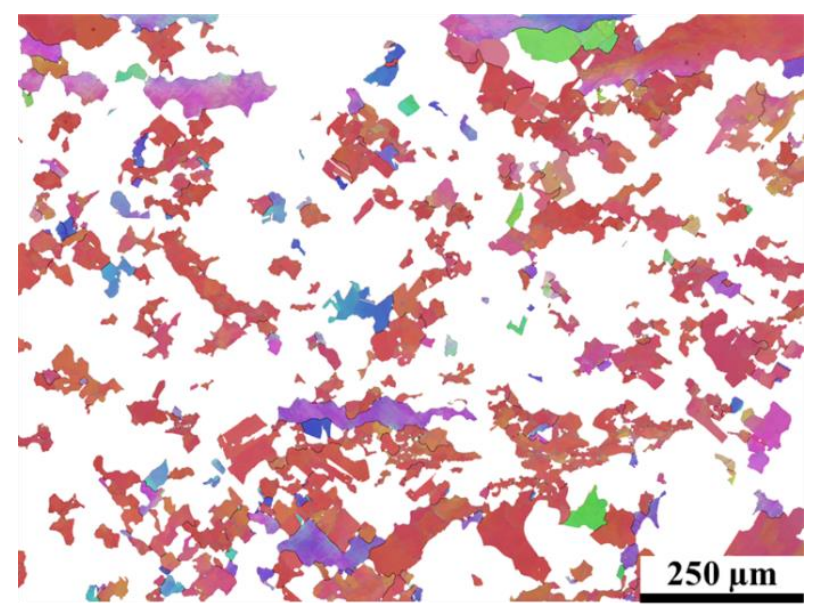

(j)

Figure 4. Inverse pole figure (IPF) maps segmented into: (a, c, e, g, i) recrystallised and (b, d, f, h, j) unrecrystallised fractions at true strains of $(a, b) 0.23$, (c, d) 0.35 , (e, f) $0.68,(g, h) 0.85$ and $(i, j)$ 1.2. $\mathrm{LAGBs}=$ grey, HAGBs $=$ black, $\Sigma 3\left(60^{\circ}\langle 111\rangle\right)=$ red. 


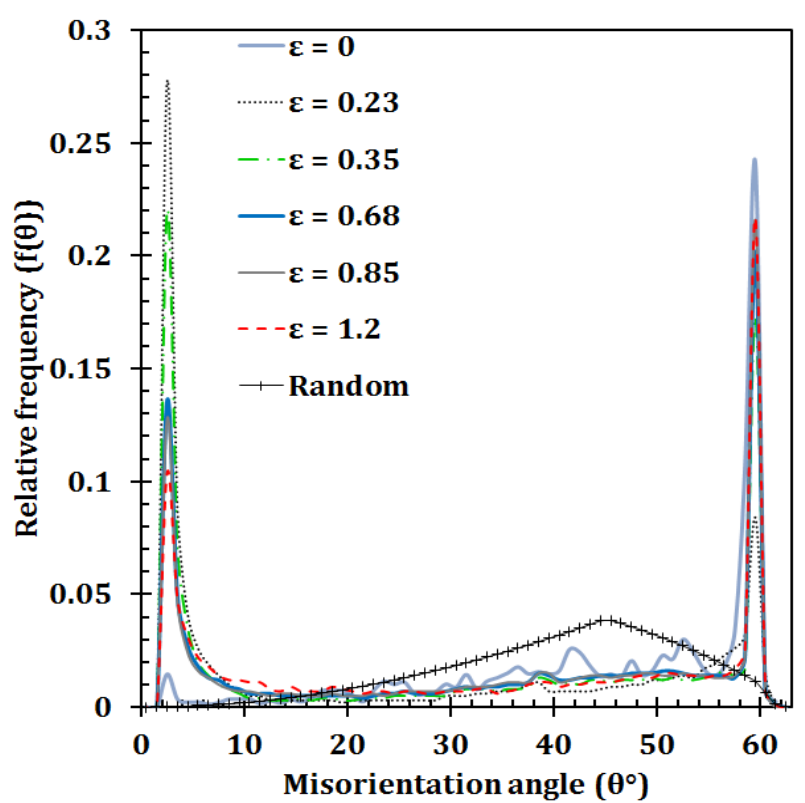

(a)

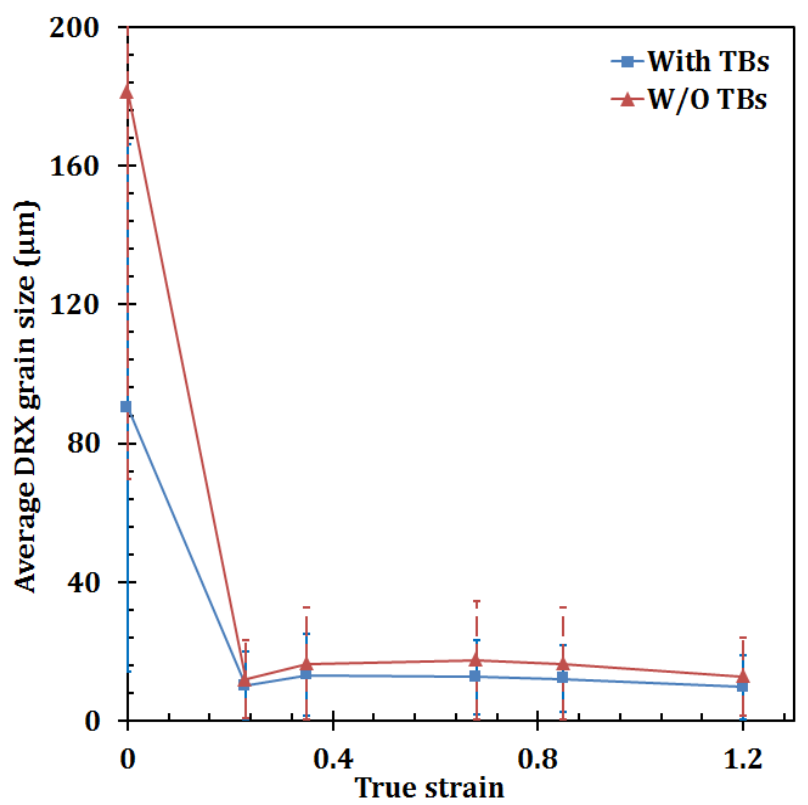

(c)

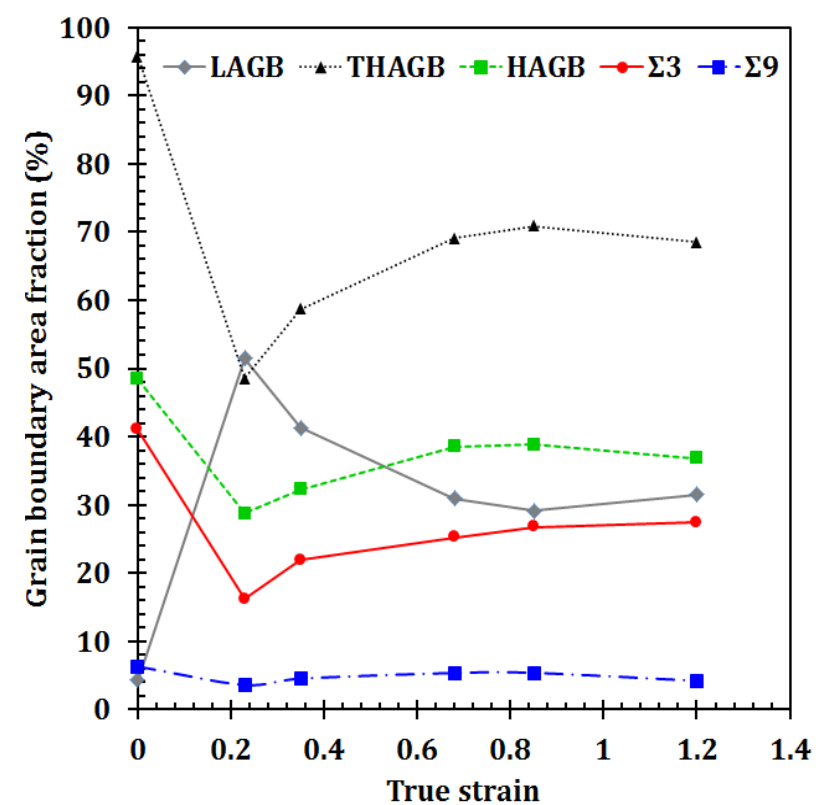

(b)

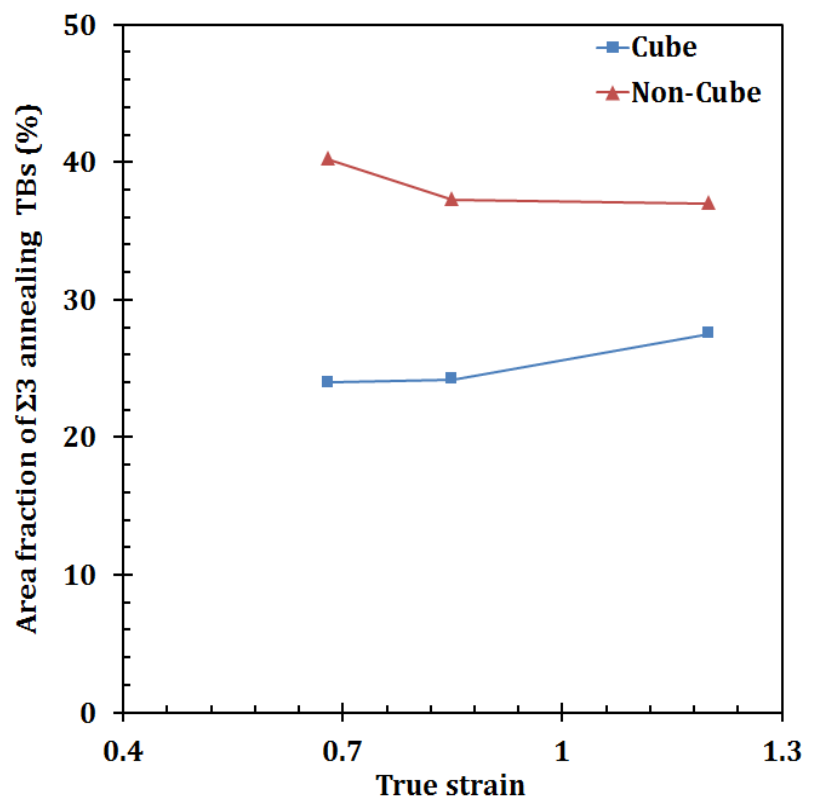

(d)

Figure 5. (a) The change in misorientation distribution as a function of true strain with representative misorientation axis distributions in the crystal coordinate system for $\Sigma 3$ and $\Sigma 9$ angular ranges. (b) Grain boundary area fraction as a function of true strain. (c) The change in average recrystallised grain size as a function of true strain with and without considering twin boundaries as grain boundaries. (d) The area fraction of $\Sigma 3$ annealing twin boundaries in dynamically recrystallised cube and non-cube oriented grains. 


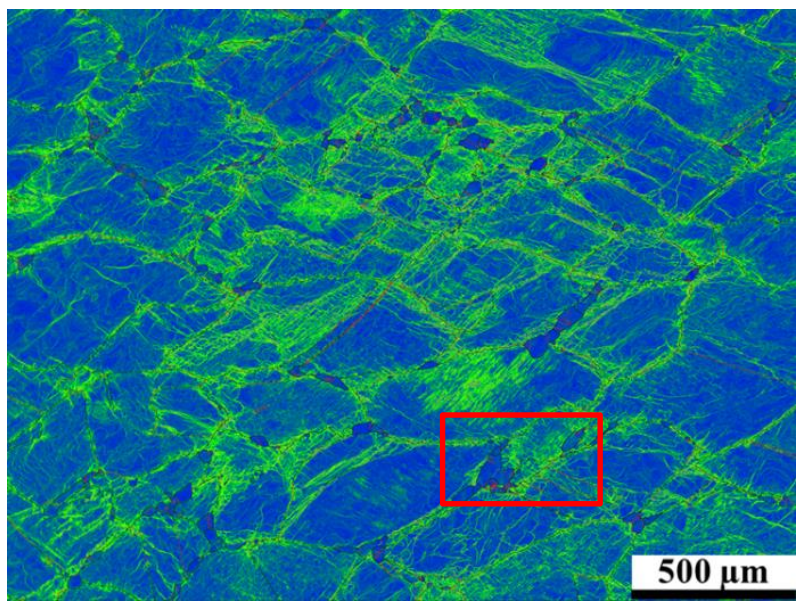

(a)

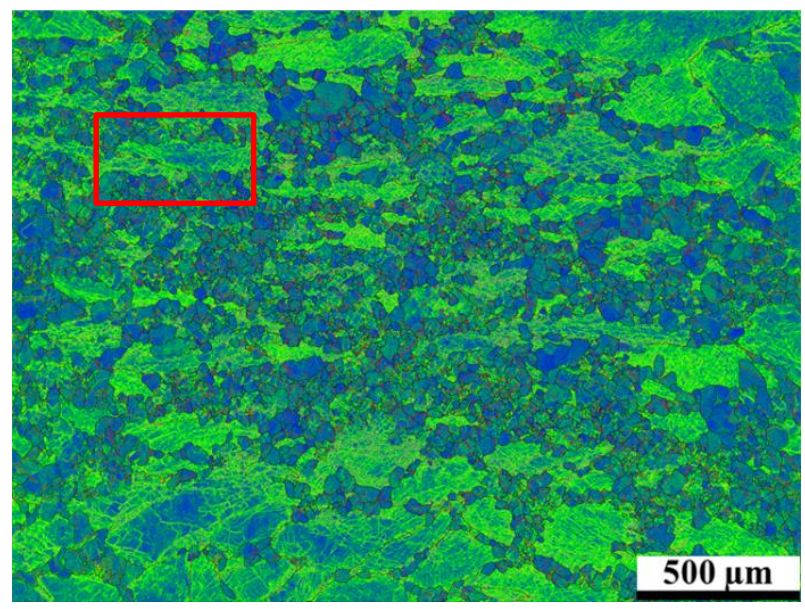

(c)

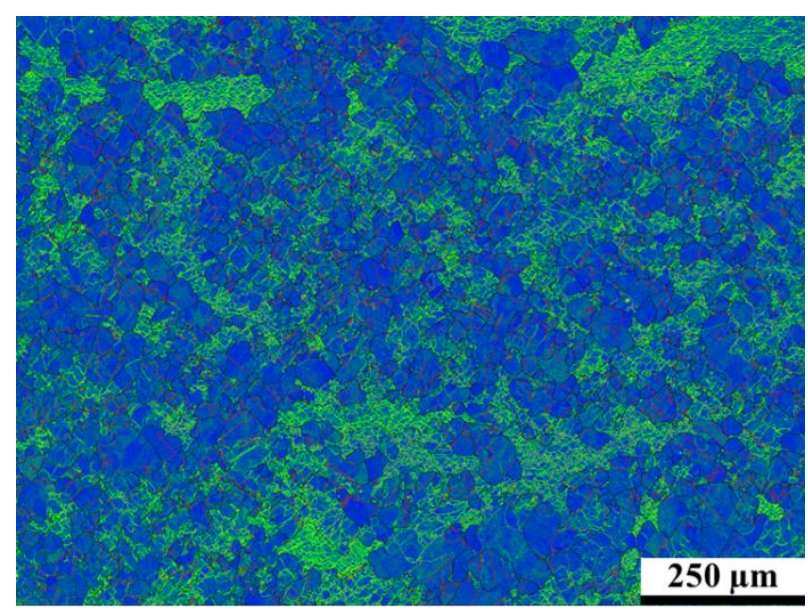

(e)

(e)

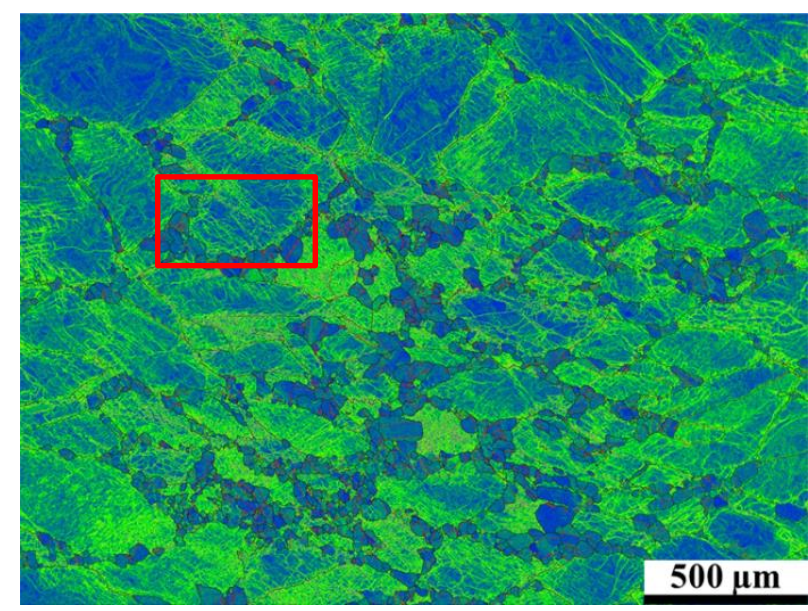

(b)

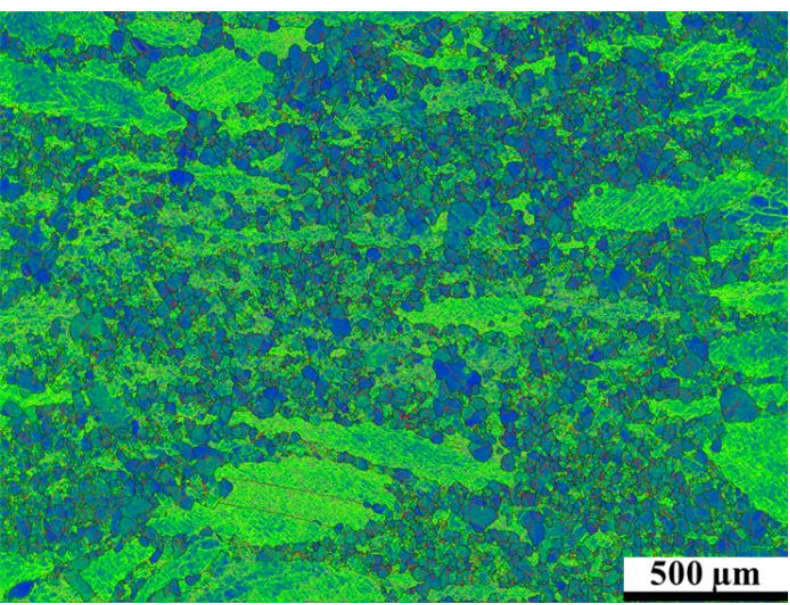

(d)

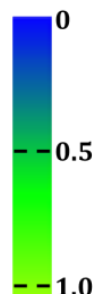

$--1.5$

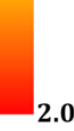

Figure 6. Intragranular local misorientation maps at true strains of (a) 0.23 , (b) 0.35 , (c) 0.68 , (d) 0.85 , and (e) 1.2. HAGBs $=$ black, $\Sigma 3\left(60^{\circ}\langle 111\rangle\right)=$ red. 


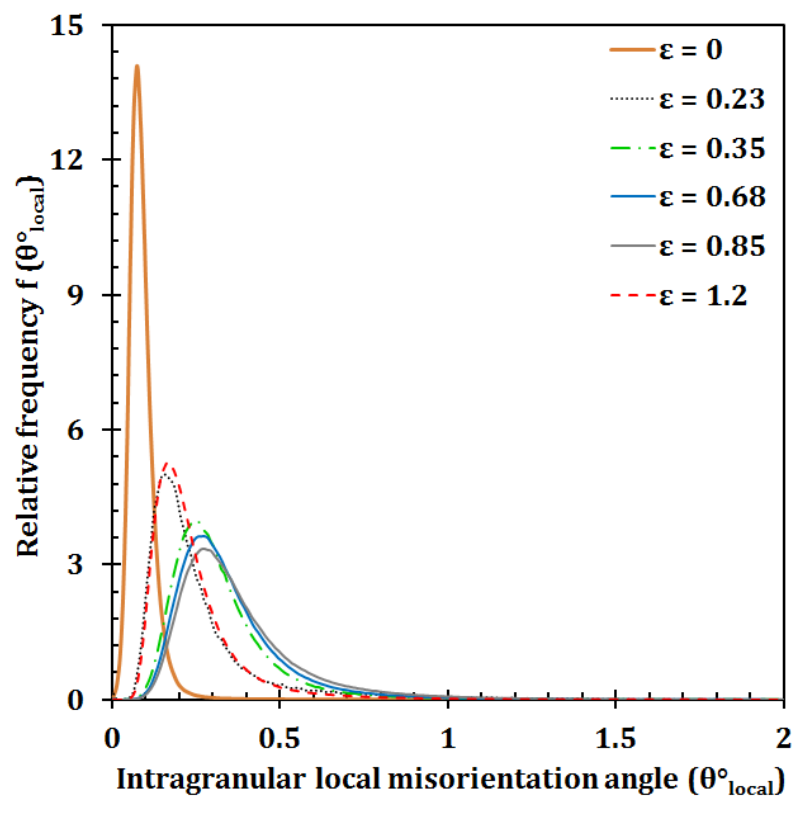

(a)

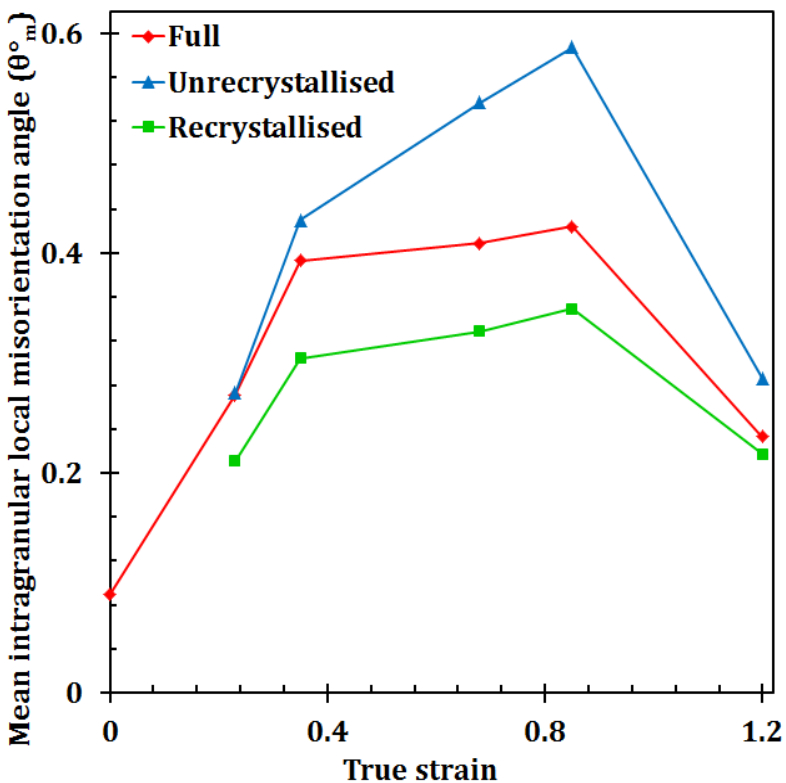

(b)

Figure 7. The change in intragranular local misorientation (a) angular distribution of the dynamically recrystallised grains and (d) mean value of the full, unrecrystallised and recrystallised fractions as a function of true strain. 


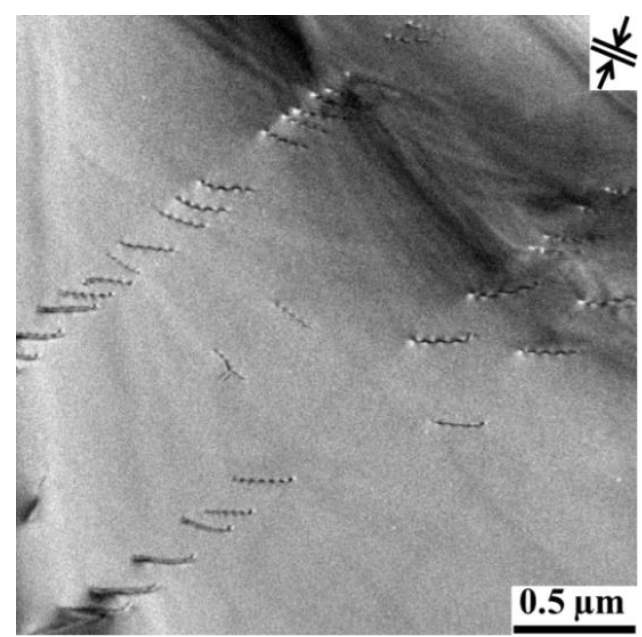

(a)

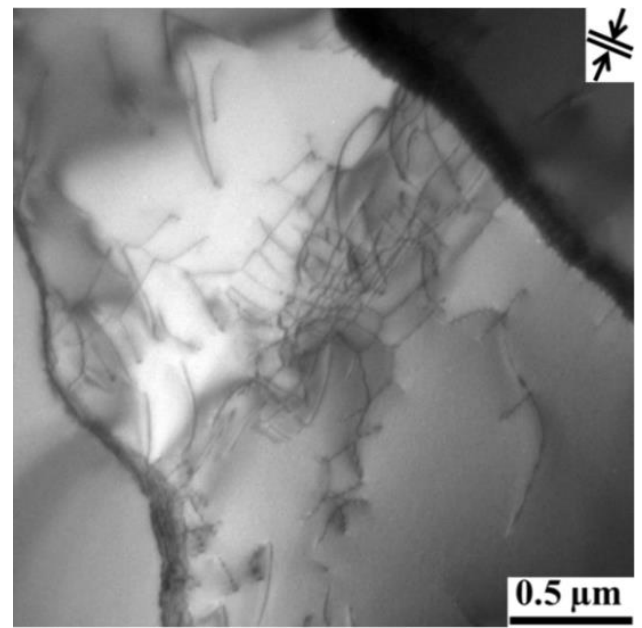

(c)

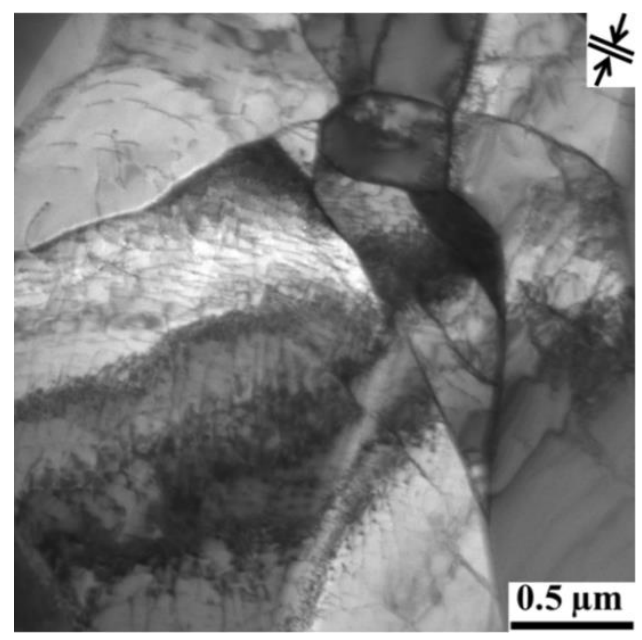

(e)

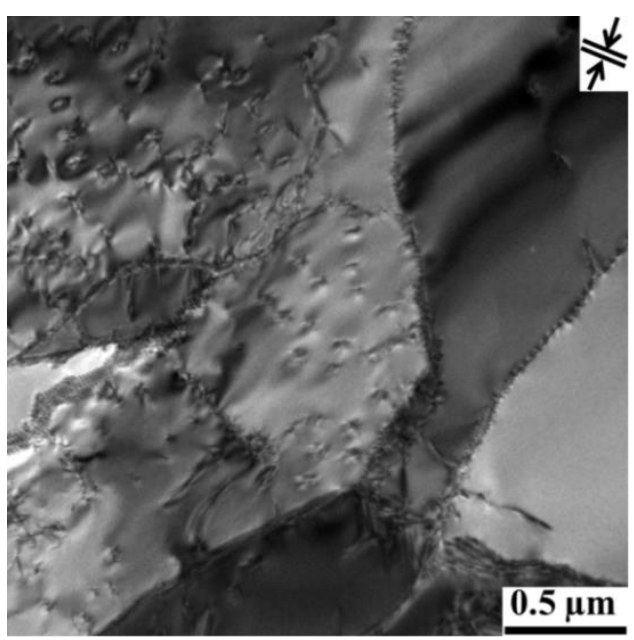

(b)

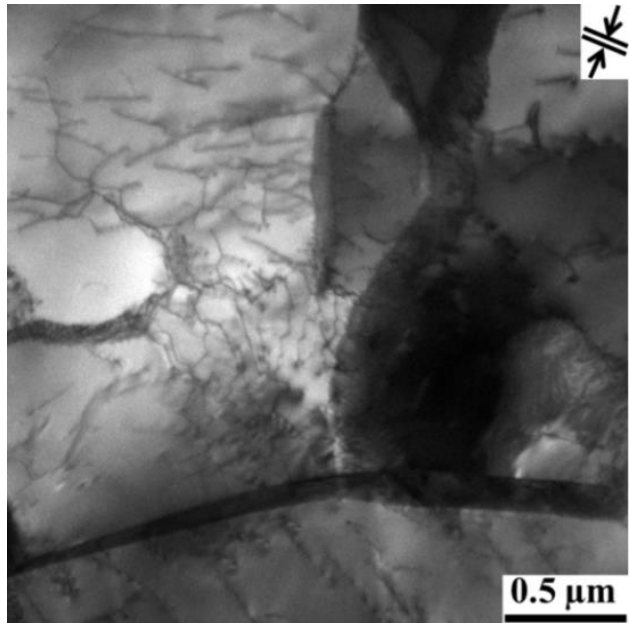

(d)

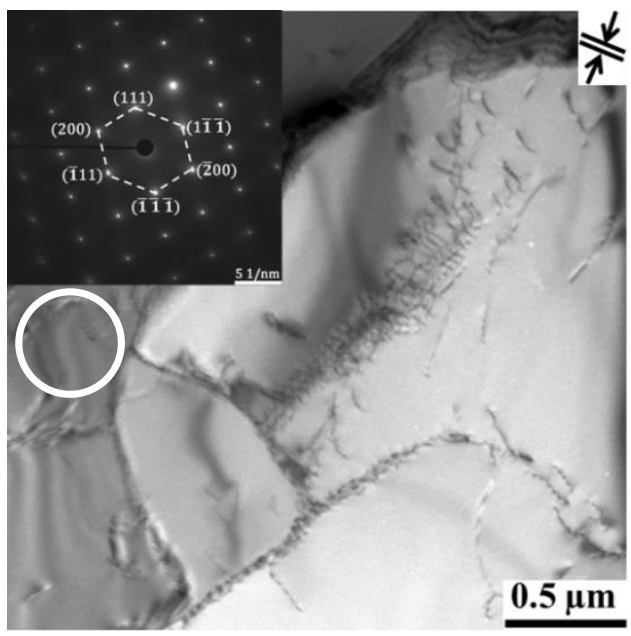

(f)

Figure 8. Bright-field images at true strains of (a) 0, (b) 0.23, (c) 0.35, (d) 0.68, (e) 0.85, and (f) 1.2. In (a-f) the zone axis is $\sim[01 \overline{1}]$. The plane strain compression direction is parallel to the ND (in rolling convention) and is denoted by black arrows in the top right insets. The inset in (f) is the selected area diffraction pattern corresponding to the area marked by the white circle. 


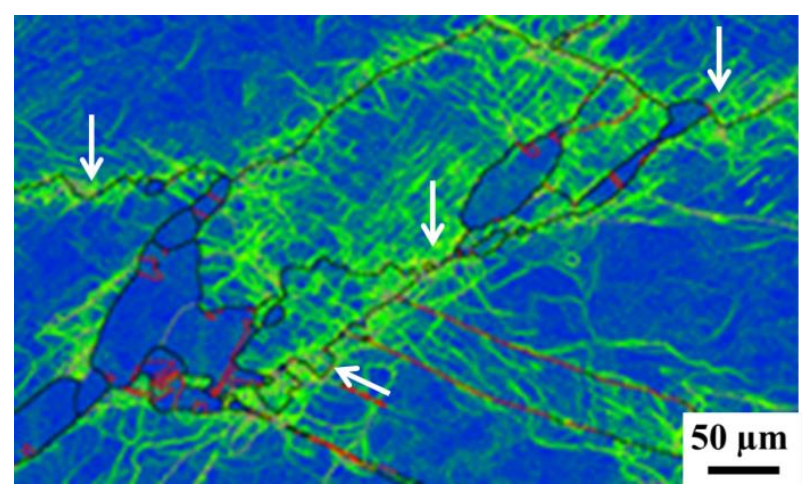

(a)

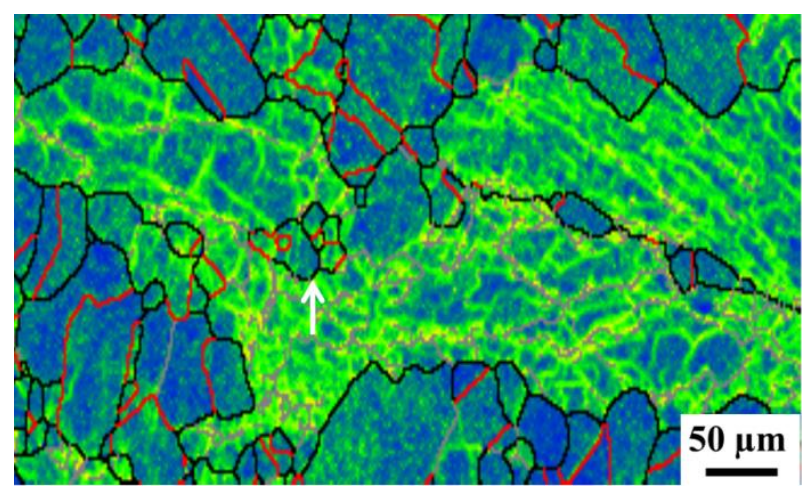

(c)

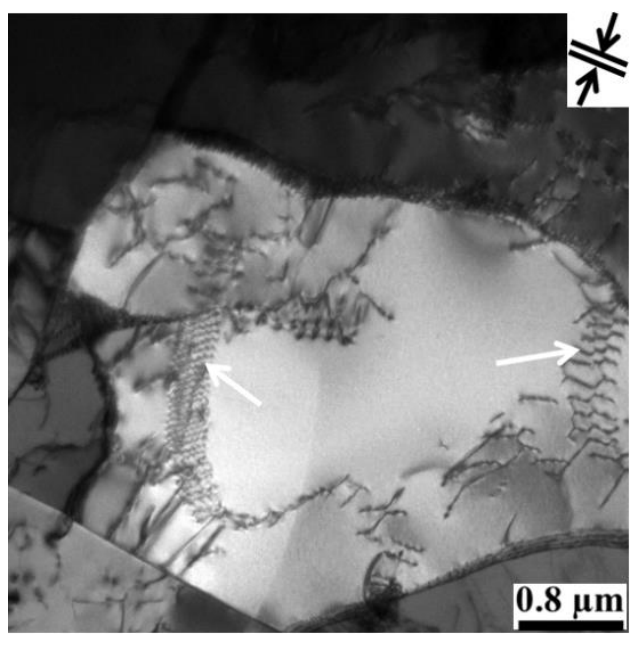

(e)

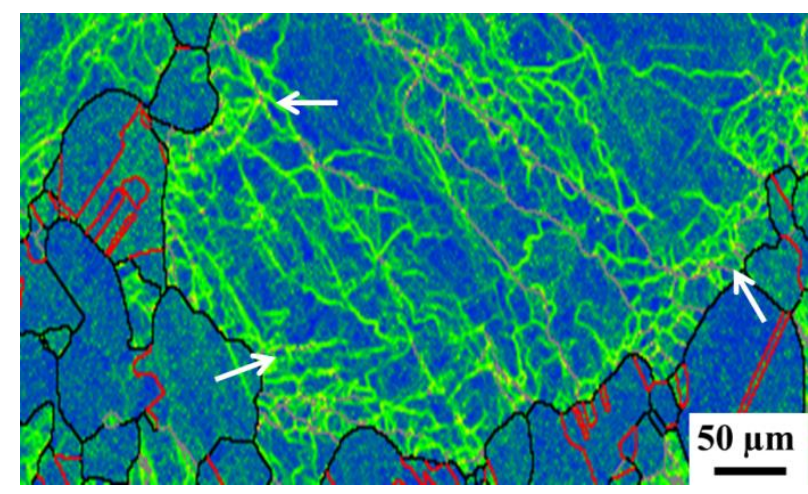

(b)

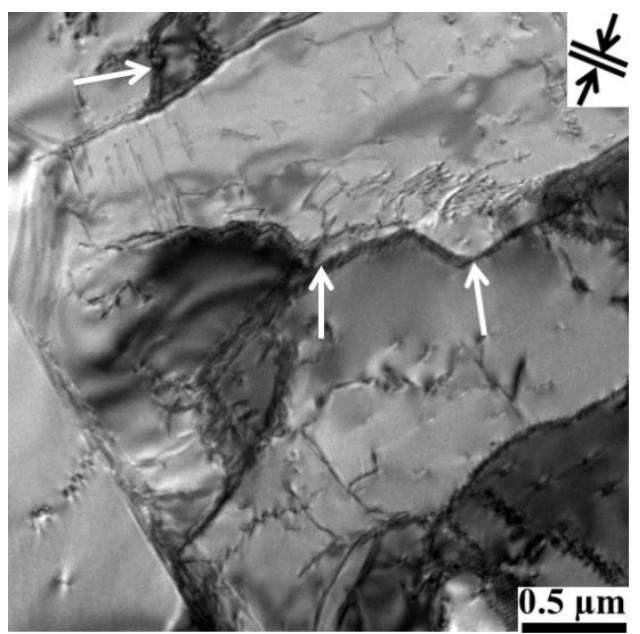

(d)

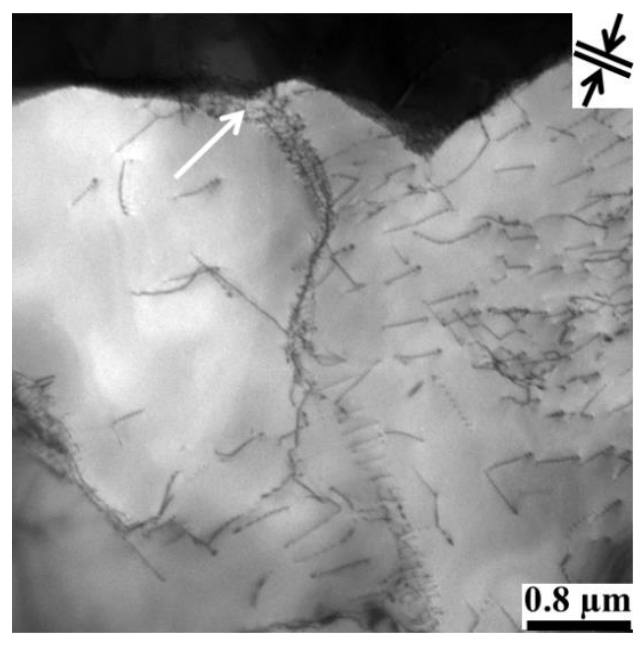

(f)

Figure 9. (a-c) Magnified intragranular local misorientation maps of selected regions of interest (demarcated by rectangular red boxes in Fig. 6) at true strains of (a) 0.23, (b) 0.35 and (c) 0.68. Bright-field images at true strains of (d) 0.23 , (e) 0.35 and (f) 0.68. In (d-f) zone axes are [01 $\overline{1}]$. In (a-c) the white arrows highlight areas of high intragranular local misorientation whereas in (d-f) the white arrows highlight dislocation arrays and/or dislocation cells near grain boundaries. 


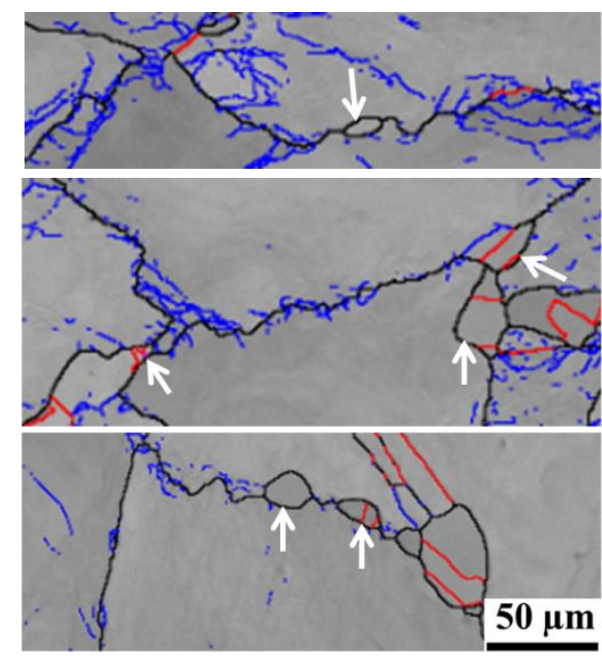

(a)

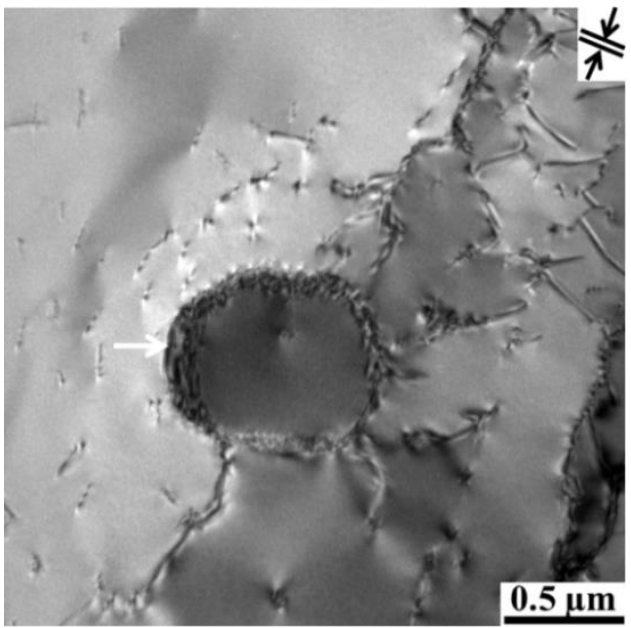

(c)

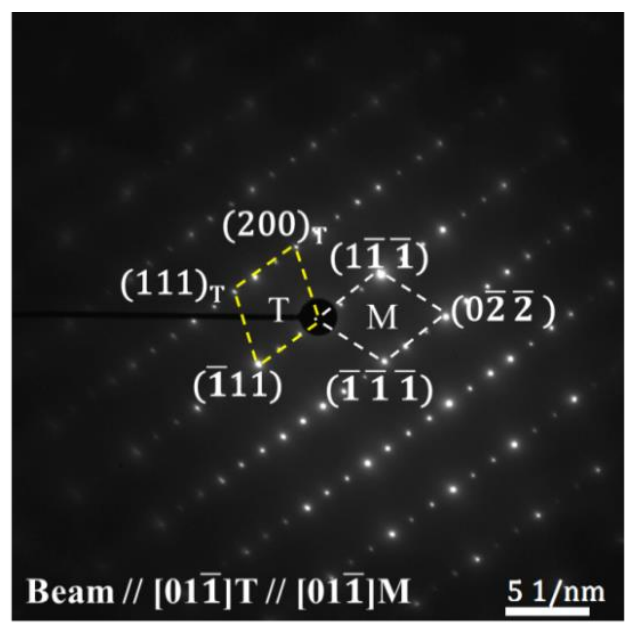

(e)

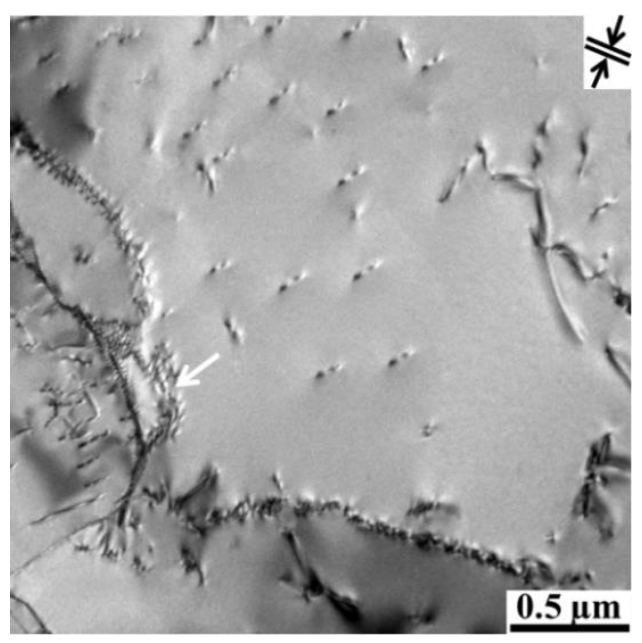

(b)

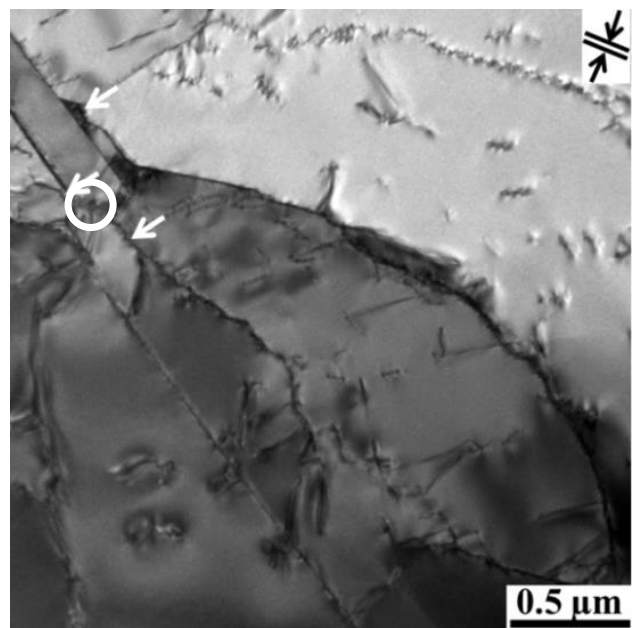

(d)

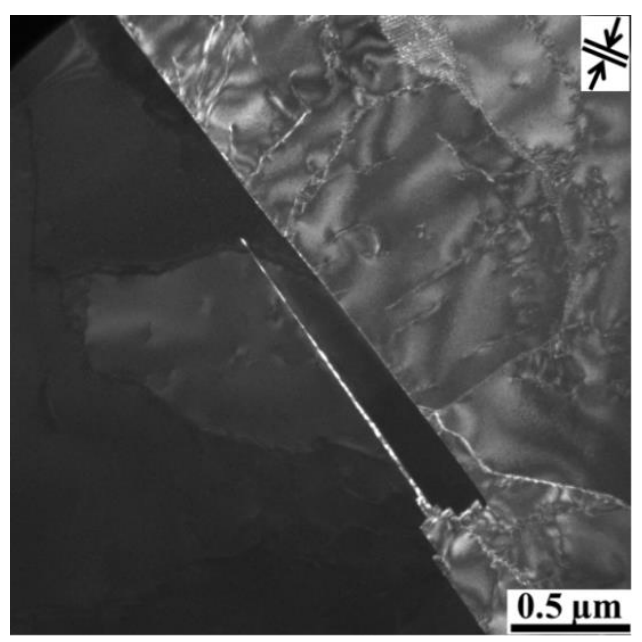

(f)

Figure 10. (a) Magnified band contrast maps of selected regions of interest and (b-d) bright-field images at $\varepsilon=0.23$. (e) A selected area diffraction pattern along the [011] zone axis of a twin and its matrix from (d) marked by a white circle with (f) the dark-field image of the twin using $[\overline{2} 00]_{T}$. In (a) LAGBs = blue, HAGBs = black, $\Sigma 3\left(60^{\circ}\langle 111\rangle\right)=$ red. In (a-d) the white arrows highlight nucleation at (a-c) original grain boundaries and (a,d) twin boundaries. 


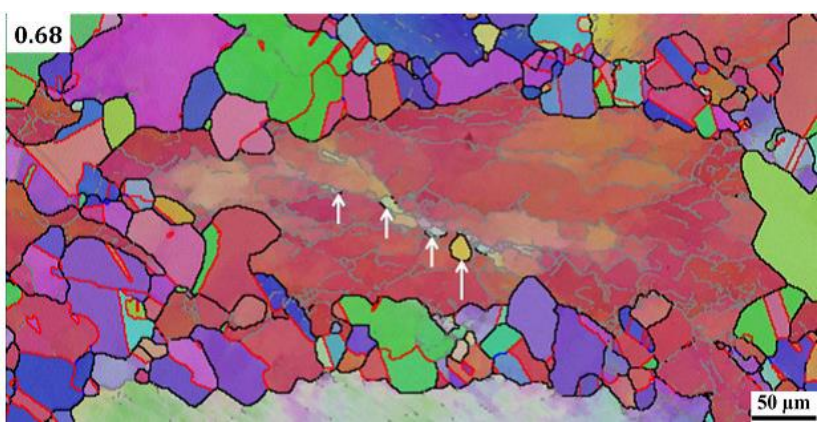

(a)

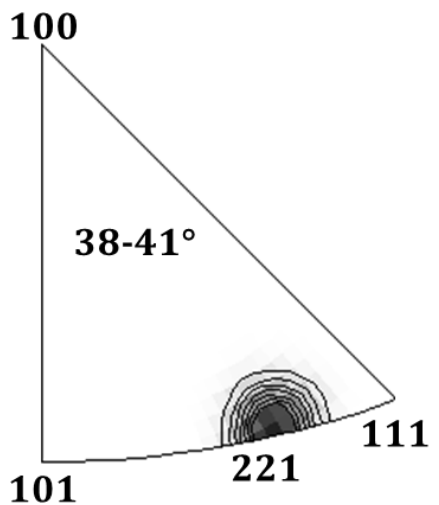

(c)

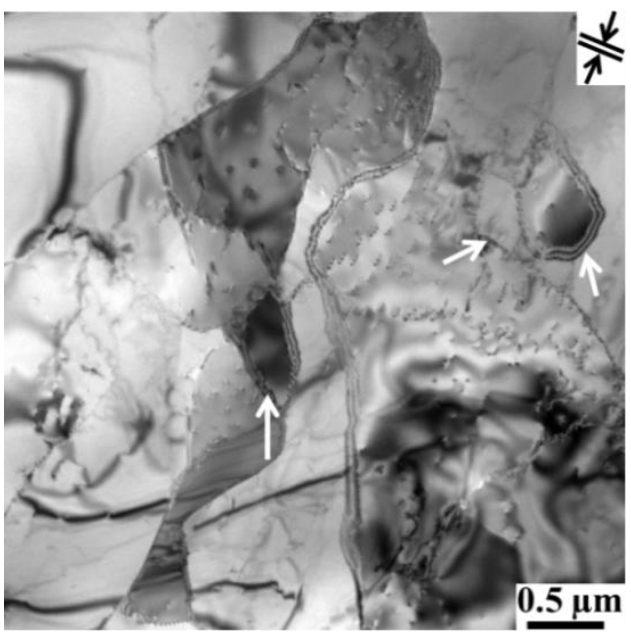

(f)

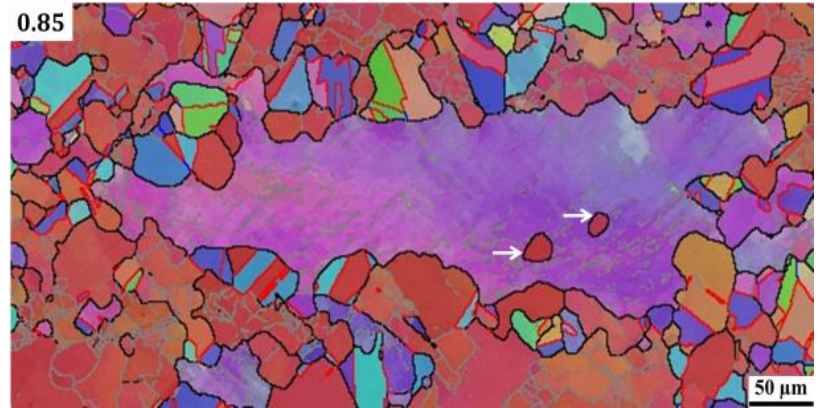

(b)

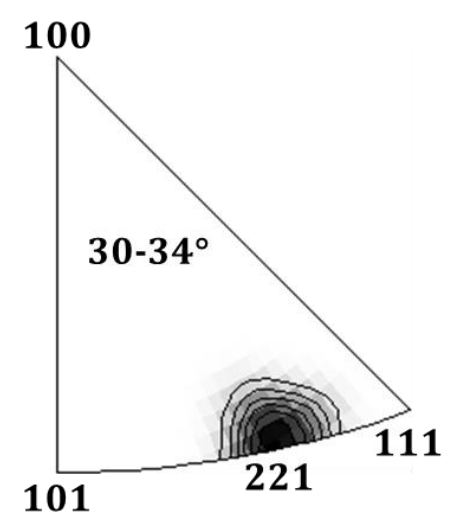

(e)

(d)

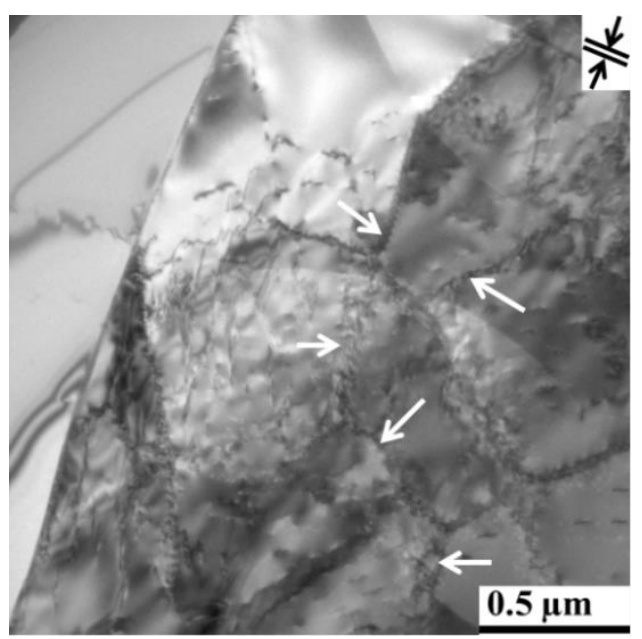

$(\mathrm{g})$

Figure 11. Magnified inverse pole figure maps of selected regions of interest at true strains of (a) 0.68 and (b) 0.85 . (c-e) Misorientation axis distributions in the crystal coordinate system of the boundaries between the nuclei and the unrecrystallised matrix demarcated by white arrows in $(a, b)$ such that (c) corresponds the rightmost nuclei in (a) while (d, e) correspond to the left and right nuclei in (b), respectively. Bright-field images at true strains of (f) 0.68 and (g) 0.85 . In (f, g) zone axes are $\sim[01 \overline{1}]$ and white arrows indicate dynamically recrystallised nuclei or subgrains. 

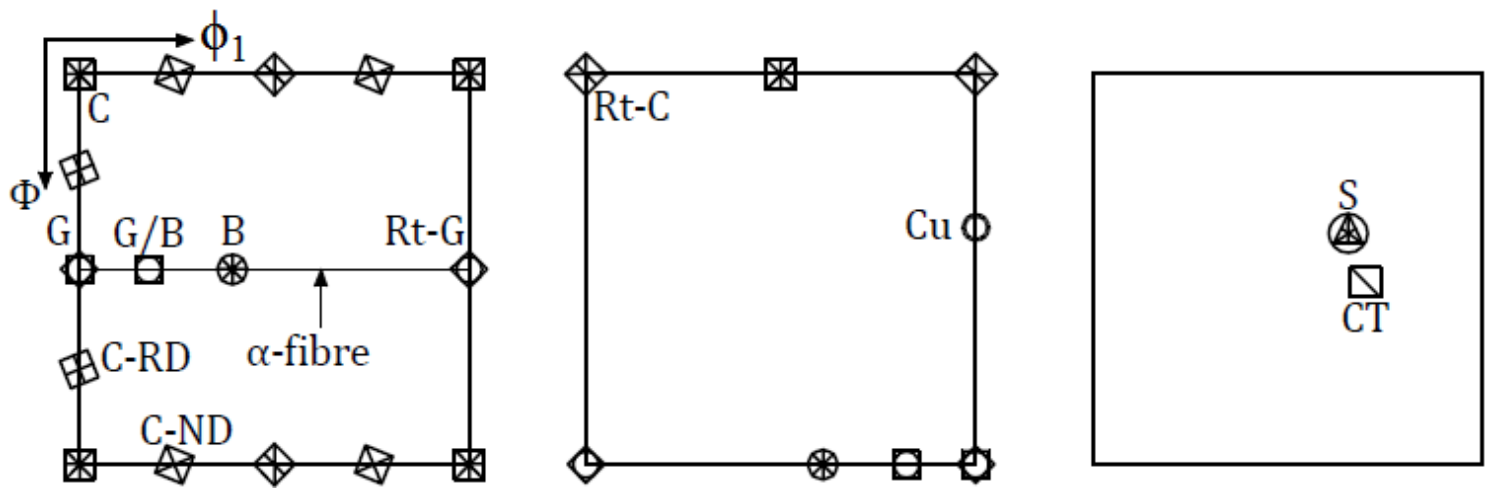

Figure 12. Schematic representation of the common texture components in fcc metals and alloys.
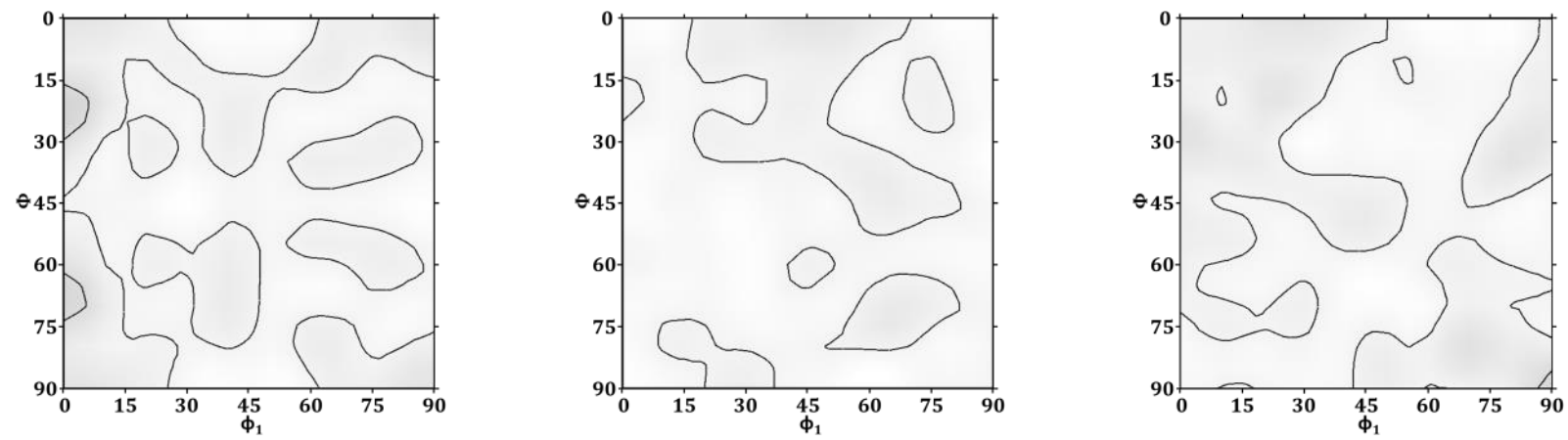

Figure 13. $\phi_{2}=0^{\circ}, 45^{\circ}$ and $65^{\circ} \mathrm{ODF}$ sections calculated from an EBSD map acquired with $10 \mu \mathrm{m}$ step size at $\varepsilon=0$. Contour levels $=2 \times$. 

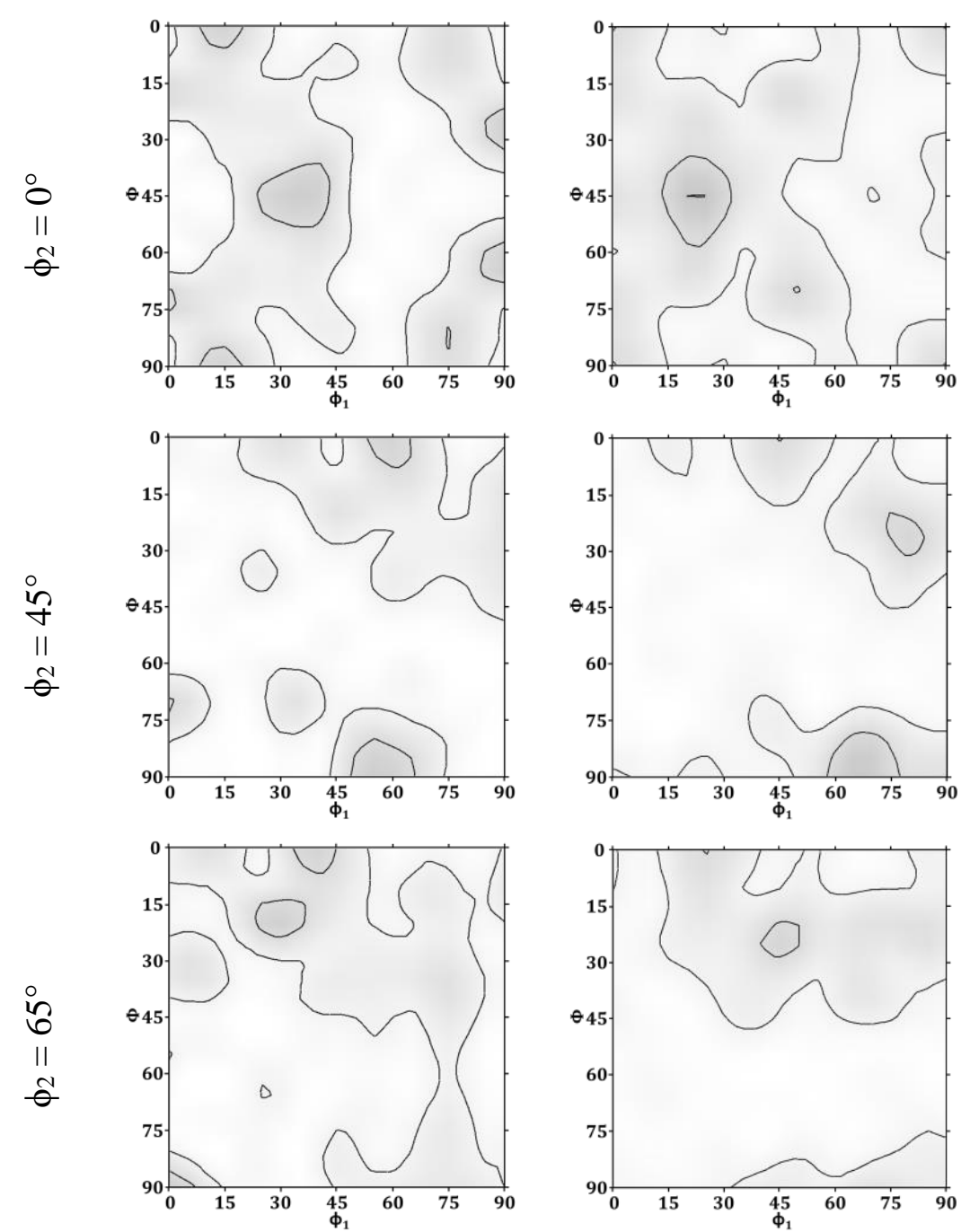

(a)

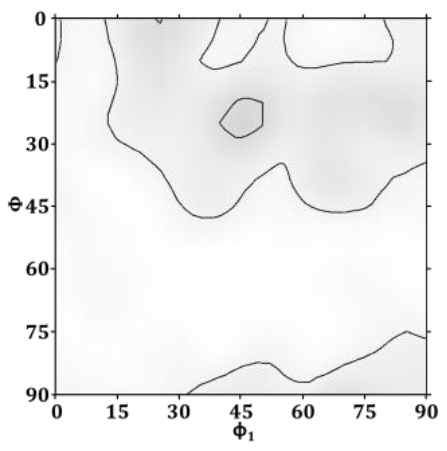

(b)
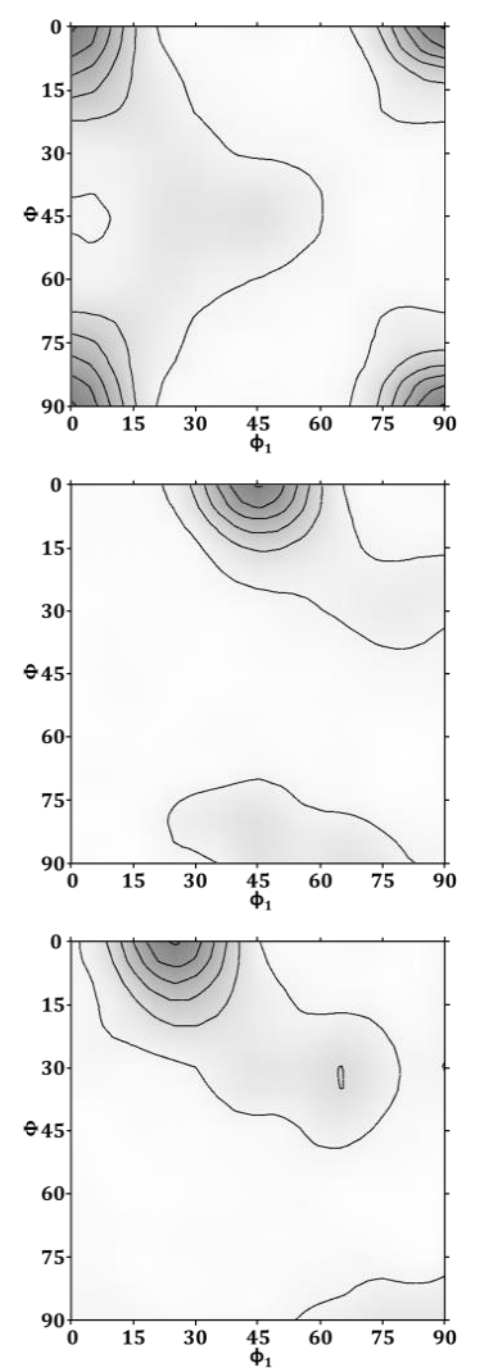

(c)
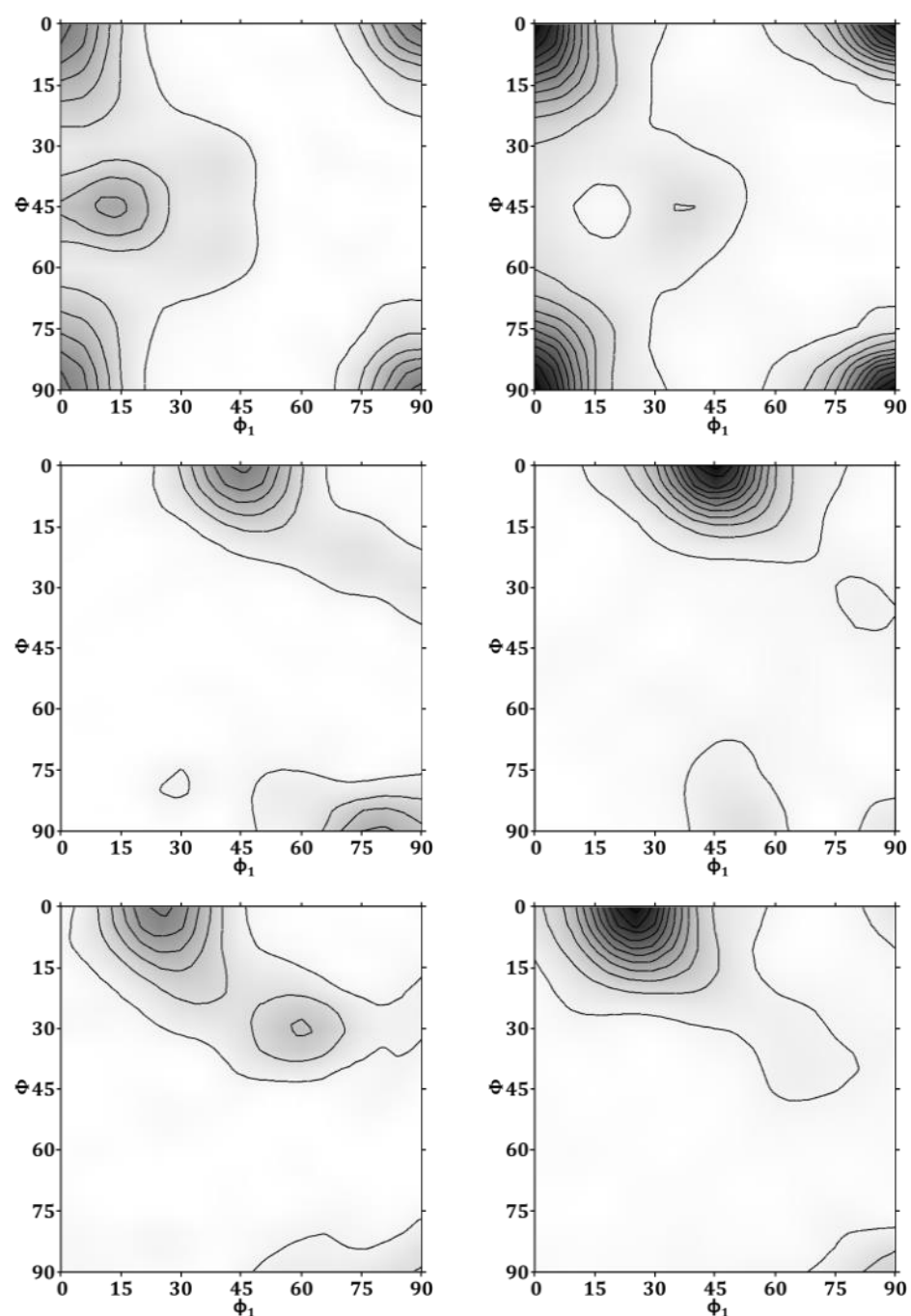

(d)

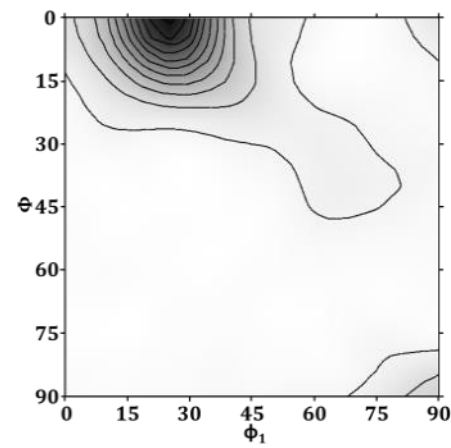

(e)

Figure 14. $\phi_{2}=0^{\circ}, 45^{\circ}$ and $65^{\circ}$ ODF sections of the full maps at true strains of (a) 0.23, (b) 0.35, (c) 0.68, (d) 0.85 and (e) 1.2 . Contour levels $=2 \times$. 

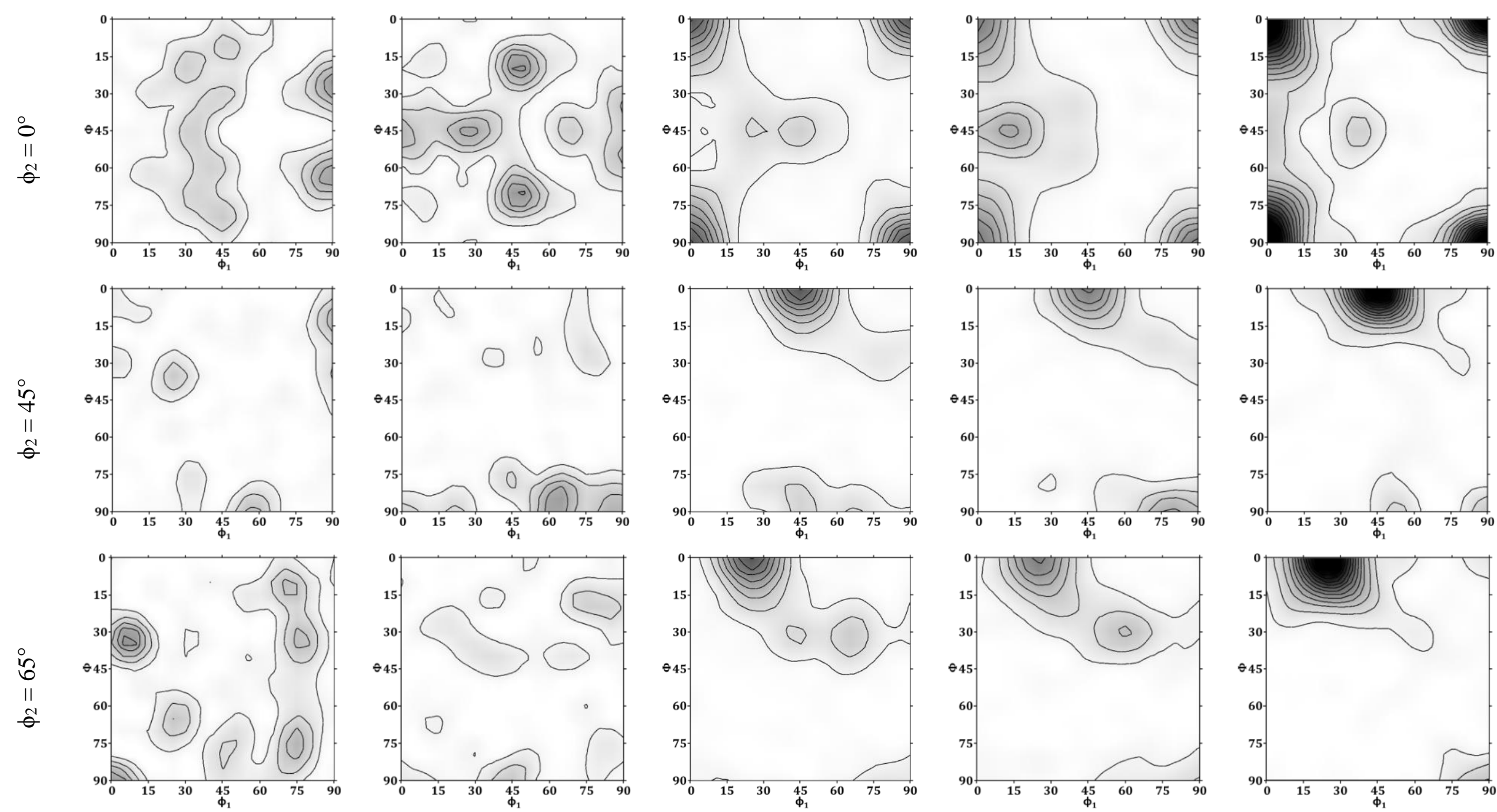

(a)
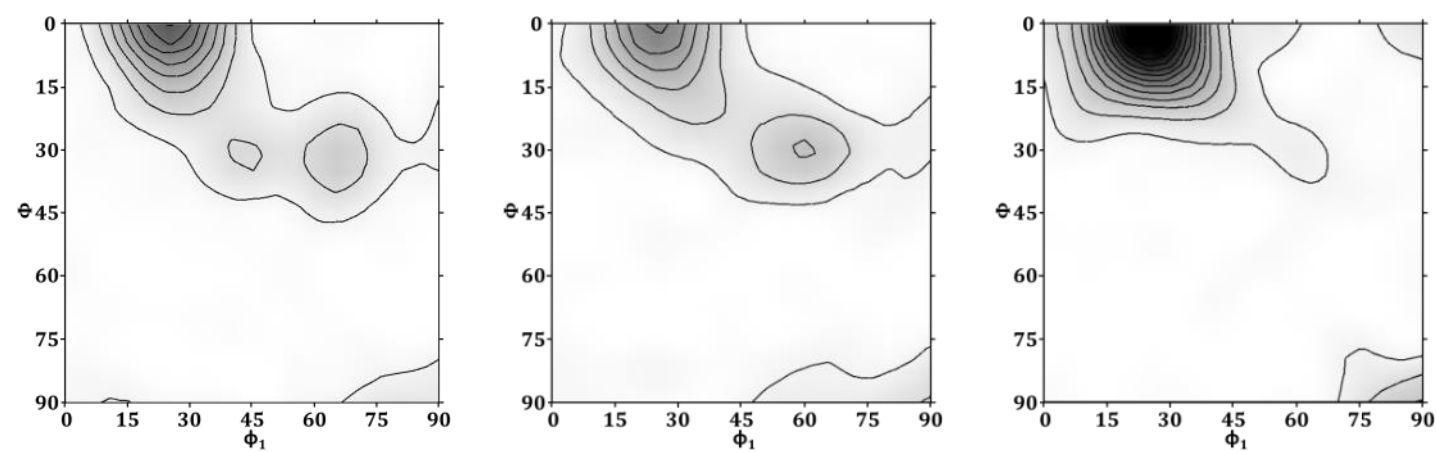

(b)

(c)

(d)

(e)

Figure $15 . \phi_{2}=0^{\circ}, 45^{\circ}$ and $65^{\circ} \mathrm{ODF}$ sections of the unrecrystallised fractions at true strains of (a) 0.23, (b) 0.35, (c) 0.68 , (d) 0.85 and (e) 1.2 . Contour levels $=2 \times$. 

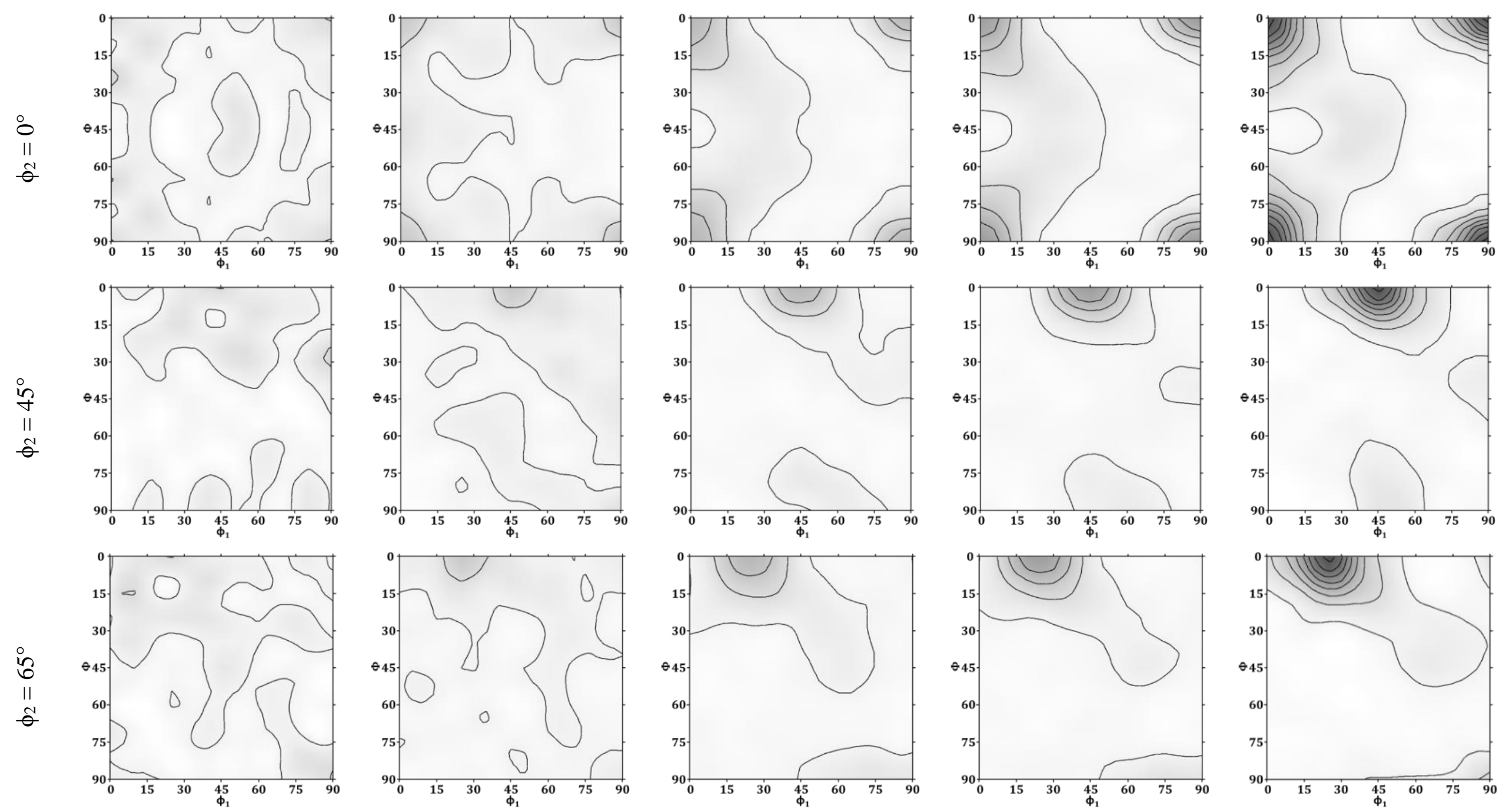

(a)

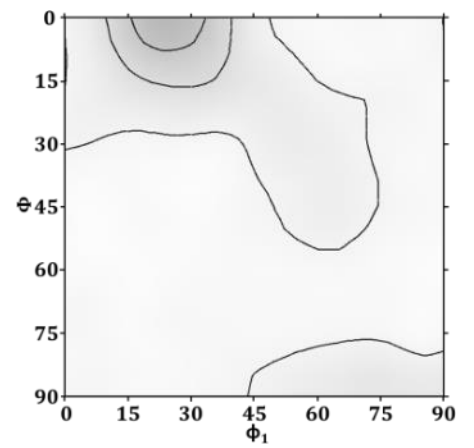

(c)

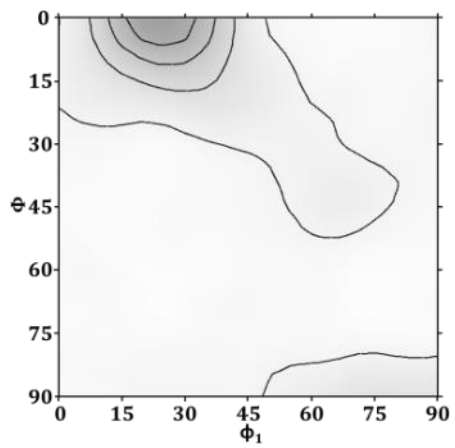

(d)

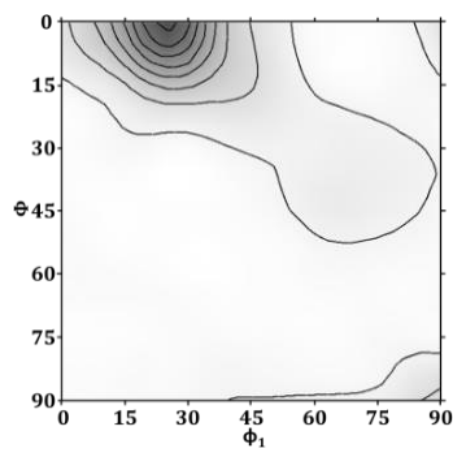

(e)

Figure 16. $\phi_{2}=0^{\circ}, 45^{\circ}$ and $65^{\circ} \mathrm{ODF}$ sections of the dynamically recrystallised fractions at true strains of (a) 0.23 , (b) 0.35 , (c) 0.68 , (d) 0.85 and (e) 1.2. Contour levels $=2 \times$. 